\title{
2009/37
}

Aging society, health and the environment

Carlotta Balestra and Davide Dottori 
CORE

Voie du Roman Pays 34

B-1348 Louvain-la-Neuve, Belgium.

Tel (32 10) 474304

Fax (32 10) 474301

E-mail: corestat-library@uclouvain.be http://www.uclouvain.be/en-44508.html 


\title{
CORE DISCUSSION PAPER
}

$2009 / 37$

\section{Aging society, health and the environment}

\section{Carlotta BALESTRA ${ }^{1}$ and Davide DOTTORI ${ }^{2}$}

May 2009

\begin{abstract}
Both environmental quality and health care expenditure are determinants of health and life expectancy, but the support for them appears to be different according to the electors' age, with a relatively larger support for health expenditure among the elderly as it is generally effective on a shorter horizon than environmental maintenance. With population aging, the political support for health care expenditure is then selfreinforcing. We cast this issue in an overlapping generations model with endogenous longevity, where lifespan depends on health care expenditure and environmental quality. We compare the long run outcomes for health care expenditure, environmental quality, lifespan, consumption and capital accumulation of an economy where agents vote over health spending and environmental maintenance, with those chosen by a social planner who takes into account also the welfare of future generations. The role played by other factors, such as the propensity for smoothing consumption or the degree of annuity markets, is also highlighted. Empirical evidence of age-biased environmental care is provided.
\end{abstract}

Keywords: population aging, endogenous longevity, environmental and health expenditure, annuity markets, inter-generational conflict, overlapping generations.

JEL Classification: I18, I12, D72, D91, H51, O40, Q20, Q28

${ }^{1}$ Université catholique de Louvain, CORE and Chair Lhoist Berghmans in Environmental Economics, B-1348

Louvain-la-Neuve, Belgium. E-mail: Carlotta.balestra@uclouvain.be

${ }^{2}$ Université catholique de Louvain, IRES, B-1348 Louvain-la-Neuve, Belgium.

E-mail: davide.dottori@uclouvain.be

The authors acknowledge financial support from Chair Lhoist Berghmans, the Belgian French speaking community (Grant ARC 03/08-235 "New macroeconomic approaches to the development problem"), and University of Bergamo. They wish to thank Thierry Bréchet, David de la Croix and Frédéric Docquier for valuable comments, participants in the Environmental Economic Seminar held at CORE in February 2007, BEED 2008 meeting held in Brussels in February 2008, AFSE conference held in Toulouse in June 2008, EAERE $16^{\text {th }}$ Annual Conference held in Gothenburg in June 2008, "Journées Générations Imbriquées, Développement et Dynamique Economique" meeting held in Aix-en-Provence in October 2008. The usual disclaimer applies.

This paper presents research results of the Belgian Program on Interuniversity Poles of Attraction initiated by the Belgian State, Prime Minister's Office, Science Policy Programming. The scientific responsibility is assumed by the authors. 



\section{Introduction}

Many Western and industrialized countries are nowadays experiencing population aging. ${ }^{1}$ In an aging society, the age structure of the electorate changes as the number of the elderly voters increases, and consequently also the outcome resulting from voting can be affected when age-sensitive issues are concerned.

Elderly voters, who do not benefit from long-term public policies, have a preference for public expenditures which are more effective in the short term, while young electors can appreciate policies yielding results over a longer horizon. This is the case of expenditures that affect health status, such as health-care spending and environmental maintenance. Both of them contribute to improve health conditions: the beneficial effect of health expenditure straightforward, and and the positive role of environmental quality on health is well-documented as well (see EEA, European Environmental Agency (2007)). The support for environmental care is however more widespread among the young ${ }^{2}$, likely because environmental friendly policies usually take more time to be effective, though often yielding long-lasting results. As the old do not enjoy future environmental improvements, they rather prefer health-care expenditures. It is worth highlighting since the beginning that we are not claiming that the elderly are not interested at all in environmental maintenance, but that they are interested to a smaller extent than the young are.

What are then the consequences in terms of health-care expenditure, environmental quality, life expectancy, consumption choices and welfare? In what respects are they different from the outcomes that a social planner would implement? Moreover, what is the role, if any, played by social, economic and technological factors, such as the degree of risk aversion, the development of annuity markets, the efficiency of environmental maintenance, the polluting effect of production and the substitutability between health-care expenditure and environmental quality? In order to assess these questions we cast the issue in a Diamond (1965) overlapping generations (OLG) framework with endogenous lifespan depending on health status. Health conditions, in turn, depend on the current level of health-care expenditure and of environmental quality, which can be improved by environ-

\footnotetext{
${ }^{1}$ To mention the most relevant examples according to World Bank's data, in Japan the share of population aged 65 years old or more has passed from $9.04 \%$ in 1980 to $19.75 \%$ in 2005; in Italy, considering the same temporal interval, it has increased from $13.15 \%$ to $19.74 \%$; in Spain from $11.21 \%$ to $16.83 \%$.

${ }^{2}$ See Section 2 for empirical evidence.
} 
mental maintenance. Two different regimes are compared. The first one is a political economy where health-care and environmental expenditures are chosen by the government to maximize the welfare of electors. In the second one, the allocation of resources is chosen by a social planner who takes into account the welfare of current and future generations and maximizes an utilitarian social welfare function consisting of the discounted sum of individuals' lifetime utilities. Therefore, the political economy differs from the social planner's approach in three main respects: firstly, the social outcome is determined by the currently living agents only. Secondly, the weight of the elderly component of the electorate is endogenously increasing as life expectancy improves. Finally, the political economy operates in a market framework where also the availability and the completeness of financial instruments such as annuities can play a further role in shaping the outcome.

This work relates to different streams of the existing literature. Since in our model lifespan is endogenous and dependent on both current healthcare expenditure and environmental quality, we refer to the literature on endogenous longevity (e.g. Blackburn and Cipriani (2002), de la Croix and Licandro (1999), Hazan and Zoabi (2006) and Cervellati and Sunde (2005)), and in particular to papers that focus on health as the main determinant of lifespan. In this respect, Chakraborty and Das (2005), for instance, postulate a positive relationship between the survival probability and the private health investment and show that, in the absence of annuities markets, the resulting interplay between income and mortality can be instrumental in generating poverty traps. Other works (cfr Chakraborty (2004), Osang and Sarkar (2005) and Bhattacharya and Qiao (2005)) model health as provided by the government through public measures. We share this feature but, whereas they assume an exogenously-given tax rate to fund health-care expenditure, in our model agents vote over taxes and their use. Moreover, following Pecchenino and Pollard (1997) and Ono and Maeda (2002), we allow for the existence of imperfect annuity markets, in order to assess the impact of a change in their degree of completeness on the social outcome.

Nevertheless, in this theoretical literature the crucial role of environmental quality on health is usually neglected, as health is usually modelled as a one-argument function, i.e. the health-care expenditure. ${ }^{3}$ On the contrary, there are several state-of-the-art empirical studies which show that the environmental conditions have a significant impact on individuals' health: e.g.

\footnotetext{
${ }^{3}$ A longevity function depending on two arguments is used in Finlay (2006), but the second one is an exogenous baseline survival probability, whilst in our paper both the arguments are endogenously determined.
} 
Bell and Davis (2001); Pope and al. (2002); Evans and Smith (2005); Katsouyanni et al. (1997); poor water quality: see Sartor and Rondia (1983); climate change: see Kunst, Looman, and Mackenbach (1993)). Two remarkable exceptions in the theoretical literature are models by Jouvet, Pestieau, and Ponthière (2007) and Pautrel (2008). Jouvet, Pestieau, and Ponthière (2007) set up an OLG model in which longevity is assumed to be affected by both environmental quality and health spending. A higher longevity has a direct beneficial effect on welfare and an indirect negative one, since it reduces the quantity of space available for each person. Since the latter effect is not internalized and environmental maintenance is not possible, the model yields an over-spending in health and hence the first-best policy involves a positive taxation on health-care expenditure. ${ }^{4}$ Differently from Jouvet, Pestieau, and Ponthière (2007), we do not postulate any space-crowding effect and we allow for environmental maintenance as an alternative measure to promote longevity. Though the causes of Jouvet, Pestieau, and Ponthière (2007)'s health-overspending are removed in our paper, over-spending in health can still result: the reason being the age-composition of voters, as the policy implemented by the government is endogenous and dependent on electors' interests. ${ }^{5}$ Pautrel (2008) using an OLG model à la Blanchard (1985) with human capital accumulation explores how the optimal growth path is influenced by the detrimental effects of pollution on life expectancy. In his model the policy that the government implements is not subject to voting, so the government is able to fully correct market externalities.

We also relate to the literature dealing with the intergenerational political divergence with respect to the level and the composition of taxes. Previous studies on environmental policy in OLG models (see, e.g., John and Pecchenino (1994); John et al. (1995)) assume that the political decisionmaking as regards environmental policy is undertaken by a short-lived government representing the currently living young, ignoring the more and more important political role played by the elderly, due to population aging. The relation between longevity and the environment is considered by Ono (2005) who analyzes the effect of increasing agents' lifespan on political decision-

\footnotetext{
${ }^{4}$ The second-best levels for the taxes on capital income and on health spending depend instead on various factors, such as the intensity of preferences for environmental quality and the pollution process: the optimal tax-rates turn out to be higher when emissions are larger or when agents' impatience is low.

${ }^{5}$ Another remarkable difference is that in Jouvet, Pestieau, and Ponthière (2007) only the young do invest in health, whereas in our model health-care expenditure is intended for the elderly people only. Both assumptions are extreme and made for analytical tractability as models work through simplifications; however, supporting health-care provision is commonly one of the prior political item for retired and elderly voters.
} 
making as regards environmental policy and finds that, in the presence of imperfect annuity markets, a greater longevity has no effect on the environmental tax and a non-positive effect on the environmental quality. Ono (2005), however, posits that lifespan is exogenous.

This paper proceeds as follows. In Section 2 we investigate for empirical evidence of age-biased environmental care. Section 3 sketches the model. Section 4 describes the equilibrium in the political economy. Section 5 deals with the case of the social planner and compares analytically the two solutions. Section 6 provides numerical analysis. Section 7 concludes.

\section{Empirical Analysis}

Is there empirical evidence for the assumption that the old care about the environment to a smaller extent than the young do? Previous researches, although not specifically focused on the effect of age, have included among the control variables a proxy for the possible impact of age. Holman and Coan (2008) including the median age in a county level dataset find no significant effect, but Kahn (2002) at different levels of analysis finds that the young have higher environmental preferences and he comments this result as related to the greater patience and willingness to accept short run sacrificies. Fort and Bunn (1998), in their analysis of referenda on nuclear power, find that opposition to nuclear plants was greatest in counties with a younger population. Thalmann (2004), using individual data and controlling for other subjective characteristics, observe that environmental concern is significantly lower among elderly people (60 years or more) than among people aged between 30 and 59 .

All these studies are generally based either on data aggregated at county or state level (e.g.: Holman and Coan (2008), Salka (2001)) or - especially for European-based studies - on individual data within the context of a single country (Thalmann (2004)). The dataset we use offers instead the opportunity to carry out an empirical analysis based on individual observations from respondents of different nationalities. The data are from the Special Eurobarometer 217/EB62.1/2004'Attitudes of European citizens towards the environment (2005). The survey is described more in details in Appendix A.1. Amongst the survey's questions, we are interested in the following one: "In your opinion, to what extent do the state of the environment influence your 'quality of life'?". Respondents could give only one answer scaled from a value of 1 (the lowest influence) to a value of 5 (the highest)? We label as env_imp2 such a variable describing the importance 
of the state of the environment for the quality of life.

For the sake of convenience we restrict the sample to respondents older than 24 years. The reason is twofold: on the one hand, this allows to be closer to our theoretical implications; ${ }^{6}$ on the other hand, this allows to simplify the treatment for some variables because of the way in which the question was made (e.g. education, see footnote 14).

A synthetic representation of the dataset is provided in Table $1 .{ }^{7}$ At the top of the table it is reported the sample distribution of env_imp2, which shows that the majority of EU citizens rates the state of the environment as very (or at least quite) important in determining the quality of their life. For the purpose of our analysis it is useful to create also the dichotomic variable (env_imp) which groups env_imp2 the positive answers on the one side and the negative ones on the other (see Table 1). As long as age is concerned, the dataset provides the age class of the respondents, shown in Table 1 as age. We can see that the sample is well balanced, being each age class roughly equally represented. As before, it is useful to aggregate the variable age by taking into account the demographic structure of our theoretical framework. Therefore we group the respondents aged 25 to 54 years old and we label them as "the young"; while respondents aged 55 years or more are grouped together as "the old". This new variable is labeled agegroup. ${ }^{8}$

In Appendix A.2 it is shown that the proportion of those considering the quality of environment as highly important ("a lot or more") is greater within the young than within the elderly group, and that the difference is statistically significant according to several tests. ${ }^{9}$ However, it could be that this happens because of the presence of correlates that are not taken into account. In order to address this issue, we take advantage of other variables available from the survey to perform an econometric analysis which allows to control for the possible effects of other determinants of environmental care, such as the level of education, the gender, the living area, whether the respondent has children, etc.

Education and political opinions are commonly found to have a signifi-

\footnotetext{
${ }^{6}$ In the model, agents work during their first period of (active) life, so empirical correspondence should be seeked disregarding the youngest people.

${ }^{7}$ In Table 1, all the observations for which the answer was "don't know" or a refusal are set as missing values for that variable and they are not shown.

${ }^{8}$ It can be observed that a half of the population is represented by those we called the young $(51.01 \%)$, while only a third of the respondents fall in the group we called the old $(36.14 \%)$. Although splitting the sample in more precise age groups would have been preferable, the aggregation shown in Table 1 is the most accurate one, given the structure of the data.

${ }^{9}$ See Appendix A.2 for details.
} 
Table 1: Variables in the dataset

\begin{tabular}{|c|c|c|c|c|}
\hline Dependent Variables & & Freq. & Percent & Cum. \\
\hline \multirow[t]{4}{*}{ env_imp2 } & not at all & 760 & 3.58 & 3.58 \\
\hline & not much & 4,477 & 21.10 & 24.69 \\
\hline & quite a lot & 9,798 & 46.18 & 70.87 \\
\hline & very much & 6,180 & 29.13 & 100.00 \\
\hline \multirow[t]{2}{*}{ env_imp } & not much or less & 5,237 & 24.69 & 24.69 \\
\hline & a lot or more & 15,978 & 75.31 & 100.00 \\
\hline \multicolumn{5}{|l|}{ Age variables } \\
\hline \multirow[t]{5}{*}{ Age } & $25-34$ & 3,996 & 18.50 & 18.50 \\
\hline & $35-44$ & 4,393 & 20.34 & 38.84 \\
\hline & $45-54$ & 4,254 & 19.69 & 58.53 \\
\hline & $55-64$ & 3,975 & 18.40 & 76.93 \\
\hline & $65+$ & 4,983 & 23.07 & 100 \\
\hline \multirow[t]{2}{*}{ Agegroup } & $25-54$ & 12,643 & 58.53 & 58.53 \\
\hline & $55+$ & 8,958 & 41.47 & 100.00 \\
\hline \multicolumn{5}{|l|}{ Control variables } \\
\hline \multirow[t]{5}{*}{ education } & no-full time education & 89 & 0.42 & 0.42 \\
\hline & 15 or less & 5,402 & 25.42 & 25.84 \\
\hline & 16-19 & 8,941 & 42.07 & 67.91 \\
\hline & more than 20 & 6,561 & 30.87 & 98.78 \\
\hline & still studying & 259 & 1.22 & 100.00 \\
\hline \multirow[t]{2}{*}{ gender } & male & 9,487 & 43.92 & 43.92 \\
\hline & female & 12,114 & 56.08 & 100.00 \\
\hline \multirow[t]{3}{*}{ area } & rural area or village & 8,178 & 38.00 & 38.00 \\
\hline & small or middle sized town & 7,830 & 36.39 & 74.39 \\
\hline & large town & 5,511 & 25.61 & 100.00 \\
\hline \multirow[t]{3}{*}{ offspring } & 0 & 15,347 & 71.05 & 71.05 \\
\hline & 1 & 2,961 & 13.71 & 84.76 \\
\hline & 2 or more & 3,293 & 15.24 & 100.00 \\
\hline \multirow[t]{2}{*}{ children } & 0 & 15,347 & 71.05 & 71.05 \\
\hline & 1 & 6,254 & 28.59 & 100.00 \\
\hline \multirow[t]{5}{*}{ polview } & left & 1,599 & 9.31 & 9.31 \\
\hline & centre-left & 3,691 & 21.49 & 30.80 \\
\hline & centre & 7,151 & 41.64 & 72.44 \\
\hline & centre-right & 3,355 & 19.53 & 91.97 \\
\hline & right & 1,379 & 8.03 & 100.00 \\
\hline \multirow[t]{3}{*}{ leftright } & left & 5,290 & 30.80 & 30.80 \\
\hline & centre & 7,151 & 41.64 & 72.44 \\
\hline & right & 4,734 & 27.56 & 100.00 \\
\hline \multirow[t]{2}{*}{ eu15 } & 0 & 7,963 & 36.86 & 36.86 \\
\hline & 1 & 13,638 & 63.14 & 100.00 \\
\hline
\end{tabular}


cant impact on the attitudes toward environmental issues. A high educated person can better appreciate the consequences of certain human effects on the environment, or she can make a stronger connection between social welfare and the environment (see Van Liere and Dunlap (1980), Thalmann (2004), Kahn and Matsusaka (1997)). ${ }^{10}$ The role of partisanship and more in general political views on environmental position seems to be quite robust across studies based on different approaches and samples (e.g. Guber (2001), Holman and Coan (2008)). Besides education and political opinions, one could expect that living in more polluted areas might make the environmental conditions a more pressuring issue (the "differential exposure" channel, see Tremblay and Dunlap (1978)). ${ }^{11}$ We also include a dummy for living in one of the countries which made up the core of the European Union, because many of the new Members States have been experiencing remarkably high levels of pollution (especially Eastern Europe countries), while in the EU-15 members green laws have a longer tradition. ${ }^{12}$ Moreover, it is especially interesting to control whether having children has any effects, since altruistic agents might rate environmental conditions important not only for themselves but also for their offspring's well-being. In our model agents are assumed to be non-altruistic and altruism can be a way for departing from the implications arising from the political economy setting we put forward in Section 4 and 6.

Let us now briefly comment the control variables reported in Table 1 and how they are coded. The variable education consists of answers to the question "What age did you leave school?". We use this piece of information first by grouping the classes into three categories and then by constructing a set of dummy variables. The first group is represented by those who attended no full-time education or left school when they were less than 15 years old, ${ }^{13}$ The second group is made up of those who left school when

\footnotetext{
${ }^{10}$ Kahn and Matsusaka (1997) suggests the further link that less educated workers are generally those who suffer more from policies of environmental protection, either because of direct consequences on their employment situation or because of the additional competition of less skilled workers displaced by affected industries.

${ }^{11}$ Salka (2001) suggests that people from rural areas can be less concerned with environmental issues not only because they are less exposed to pollution but also because they are usually more economically dependent on industries which use natural resources.

${ }^{12}$ Given data unavailability we could not control directly for income, though it is usually correlated with education. Previous studies, however, do not find a robust evidence for the impact of income: while, for instance, Kahn and Matsusaka (1997) find that income matters, but in Thalmann (2004) such a conclusion is not supported as income is not a clear-cut determinant of the acceptance of green taxes.

${ }^{13}$ Grouping the class of those with no full-time education with the immediately upper class is a matter of convenience, since the no full-time education class is made up only of
} 
they were at least 15 and younger than 20, while the third group joins those who left school when they were at least 20 years old and those who are still studying. ${ }^{14}$ Then the dummies mededu and hiedu are created, where the former is 1 if the respondent was at least 15 years old when leaving school (so the second and the third groups), and the latter is 1 when the respondent stopped full-time education when she was aged at least 20 years or if she is still studying (so only the third group). ${ }^{15}$

The variable gender takes the value 1 if the respondent is a female, the dummy variable eu15 is 1 if the respondent is a citizen of one of the EU-15 countries, the dummy variable children is 1 if the respondent has at least one child less than 15 years old living in the household. By means of dummy variables we include the qualitative variables area (the living area of the respondent, which is classified either as "rural area or village", or "small or middle sized town", or "large town") and leftright (the political views, classified as left, center, right).

\section{Results}

We consider a probit model where the dependent variable is env_imp and an order probit model where the dependent variable is env_imp2. All coefficients are significantly robust to the replacement of the assumption of a normal distribution with a logistic one. ${ }^{16}$

In the first two columns of Table 2 the coefficients of the probit regression with the dependent variable env_imp can be observed. In the first column the regressor for age is represented by the dichotomic variable agegroup, while in the second column age is represented by the more analytical variable age. The coefficients are all robust to the use of different proxies for the controls. ${ }^{17}$ The coefficient of agegroup is negative and 99\% significant, supporting the idea that the elderly group feels a relative lower concern for environmental conditions than the young.

89 observations out of a total of 21,252 . The regressions' results are robust with respect to keeping distinct these two classes.

${ }^{14}$ Including the answer "still studying" in the highest level of education is appropriate as the sample is restricted to people aged 25 or more. Out of 259 still-studying respondents after the sample's restriction, 210 are less than 35 years old, 37 between 35 and 44 years old, while only 12 are distributed in the eldest age classes.

${ }^{15}$ Therefore hiedu by referring to a subset of mededu should capture the marginal effect of the highest class of education.

${ }^{16}$ Logit regressions results are available from the authors upon request.

${ }^{17}$ The results obtained by using different proxies are omitted for the sake of brevity but available upon request. In particular, the regressions have been performed by substituting leftright with a more detailed set of dummy variables for the political views (polview), and by replacing children with several alternative measures (log of number of children, number of children, a separate dummy when children are at least two, etc.). 
Table 2: Probit analysis

\begin{tabular}{|c|c|c|c|c|c|c|c|c|}
\hline \multirow[b]{2}{*}{ agegroup } & \multicolumn{4}{|c|}{$\begin{array}{c}\text { Probit regressions } \\
\text { env_imp }\end{array}$} & \multicolumn{4}{|c|}{$\begin{array}{c}\text { Order probit regressions } \\
\text { env_imp2 }\end{array}$} \\
\hline & $\begin{array}{r}-0.0822 \\
(0.0253)\end{array}$ & & - & & $\begin{array}{r}-0.0708 \\
(0.0200)\end{array}$ & $* * *$ & - & \\
\hline age & - & & $\begin{array}{r}-0.0256 \\
(0.0091)\end{array}$ & $* * *$ & - & & $\begin{array}{r}-0.0257 \\
(0.0072)\end{array}$ & $* * *$ \\
\hline center-parties & $\begin{array}{r}-0.0360 \\
(0.0255)\end{array}$ & & $\begin{array}{r}-0.0366 \\
(0.0255)\end{array}$ & & $\begin{array}{r}-0.0292 \\
(0.0199)\end{array}$ & & $\begin{array}{r}-0.0298 \\
(0.0199)\end{array}$ & \\
\hline right-wing parties & $\begin{array}{r}-0.0697 \\
(0.0280)\end{array}$ & $* *$ & $\begin{array}{r}-0.0712 \\
(0.0280)\end{array}$ & $* *$ & $\begin{array}{r}-0.0354 \\
(0.0220)\end{array}$ & & $\begin{array}{r}-0.0359 \\
(0.0220)\end{array}$ & \\
\hline mededu & $\begin{array}{r}-0.0338 \\
(0.0286)\end{array}$ & & $\begin{array}{r}-0.0326 \\
(0.0288)\end{array}$ & & $\begin{array}{r}-0.0018 \\
(0.0226)\end{array}$ & & $\begin{array}{r}-0.0042 \\
(0.0228)\end{array}$ & \\
\hline hiedu & $\begin{array}{r}0.1364 \\
(0.0251)\end{array}$ & $* * *$ & $\begin{array}{r}0.1354 \\
(0.0251)\end{array}$ & $* * *$ & $\begin{array}{r}0.1596 \\
(0.0197)\end{array}$ & $* * *$ & $\begin{array}{r}0.1584 \\
(0.0197)\end{array}$ & $* * *$ \\
\hline female & $\begin{array}{r}0.0410 \\
(0.0214)\end{array}$ & $*$ & $\begin{array}{r}0.0416 \\
(0.0214)\end{array}$ & $*$ & $\begin{array}{r}0.0291 \\
(0.0169)\end{array}$ & $*$ & $\begin{array}{r}0.0295 \\
(0.0169)\end{array}$ & $*$ \\
\hline small town & $\begin{array}{r}0.0755 \\
(0.0247)\end{array}$ & $* * *$ & $\begin{array}{r}0.0753 \\
(0.0247)\end{array}$ & $* * *$ & $\begin{array}{r}0.0432 \\
(0.0195)\end{array}$ & $* *$ & $\begin{array}{r}0.0431 \\
(0.0195)\end{array}$ & $* *$ \\
\hline big city & $\begin{array}{r}0.1459 \\
(0.0276)\end{array}$ & $* * *$ & $\begin{array}{r}0.1450 \\
(0.0277)\end{array}$ & $* * *$ & $\begin{array}{r}0.1441 \\
(0.0217)\end{array}$ & $* * *$ & $\begin{array}{r}0.1429 \\
(0.0217)\end{array}$ & $* * *$ \\
\hline children & $\begin{array}{r}0.0252 \\
(0.0268)\end{array}$ & & $\begin{array}{r}0.0265 \\
(0.0274)\end{array}$ & & $\begin{array}{r}0.0202 \\
(0.0210)\end{array}$ & & $\begin{array}{r}0.0160 \\
(0.0214)\end{array}$ & \\
\hline eu15 & $\begin{array}{r}-0.1901 \\
(0.0231)\end{array}$ & $* * *$ & $\begin{array}{r}-0.1085 \\
(0.0231)\end{array}$ & $* * *$ & $\begin{array}{r}-0.0405 \\
(0.0181)\end{array}$ & $* *$ & $\begin{array}{r}-0.0406 \\
(0.0181)\end{array}$ & $* *$ \\
\hline const & $\begin{array}{r}0.8433 \\
(0.0862)\end{array}$ & $* * *$ & $\begin{array}{r}0.7474 \\
(0.0684)\end{array}$ & $* * *$ & & & & \\
\hline cut1 & & & & & $\begin{array}{r}-2.3631 \\
(0.0730)\end{array}$ & & $\begin{array}{r}-2.3008 \\
(0.060)\end{array}$ & \\
\hline cut2 & & & & & $\begin{array}{r}-1.7848 \\
(0.0696)\end{array}$ & & $\begin{array}{r}-1.7223 \\
(0.0560)\end{array}$ & \\
\hline $\begin{array}{l}\text { cut3 } \\
\text { cut4 }\end{array}$ & & & & & $\begin{array}{r}-0.7304 \\
(0.0682) \\
0.4968 \\
(0.0681)\end{array}$ & & $\begin{array}{r}-0.6679 \\
(0.05423) \\
0.5593 \\
(0.0542)\end{array}$ & \\
\hline $\begin{array}{l}\text { Number of obs }= \\
\text { LR } \chi_{(10)}^{2}= \\
\text { Prob }>\chi^{2}= \\
\text { Pseudo } R^{2}=\end{array}$ & $\begin{array}{r}16678 \\
118.00 \\
0.0000 \\
0.0064\end{array}$ & & $\begin{array}{r}16678 \\
105.27 \\
0.0000 \\
0.0057\end{array}$ & & $\begin{array}{r}16678 \\
188.01 \\
0.0000 \\
0.0046\end{array}$ & & $\begin{array}{r}16678 \\
186.90 \\
0.0000 \\
0.0046\end{array}$ & \\
\hline
\end{tabular}

*: $90 \%$; **: $95 \%$; ***:99\% 
Another significant coefficient is the one of the highest class of education (but not that of the intermediate one), suggesting that only the highest level of education has a clear positive impact on environmental care. Women appear to care significantly more than men about environmental conditions ${ }^{18}$, while citizens of the new Member States are more likely to be concerned with environmental problems than citizens of EU-15 countries, probably because of the high levels of pollution that these countries have been experiencing. Furthermore, left-wing people are found to be significantly more concerned than right-wing ones (but not than center-parties sympathizers). ${ }^{19}$ Living in towns, especially if big, has an impact on environmental concern, likely because of the greater exposure to pollution. ${ }^{20}$ Finally, we notice with interest that having children turns out to have no significant impact (even if the sign is positive) on the environmental care as measured by env_imp.

It is now interesting to check whether the results are robust to a more disaggregated classification of age classes. This is done in column 2 of Table 2 by using age. Although in absolute value the coefficient for the age variable gets smaller, it is still negative and significant. All the other results commented for column 1 are substantially confirmed. This provides support for the assumption that the concern for environmental problems is decreasing in age.

However, it might be that, even if the old caring for environmental conditions are less, their care could be deeper. Therefore, we use the variable env_imp2, which provides a more disaggregated statement of the environmental care. Since in env_imp2 four ordinal levels of environmental concern are expressed, we perform order probit regressions. Similarly to column 1 , column 3 considers age as represented by agegroup, while in column 4 (similarly to column 2) age is used. ${ }^{21}$ The negative sign and the statistical significance for the coefficient of the variable capturing the age effect are confirmed also by the order probit approach. Age is found to have a negative impact on environmental care also when the latter is divided into 4 classes of opinion. Being left-wing people is no more significant in determining the attitudes towards the environment. Results for the remaining coefficients

\footnotetext{
${ }^{18}$ This result contrasts with Thalmann (2004), who finds no gender effect on environmental concerns.

${ }^{19}$ A similar role of leftist affinities is found by Daugbjerg and Svensen (2001).

${ }^{20}$ This result is in accordance with what found by Holman and Coan (2008) who use as a regressor the share of people in the county living in rural areas, and by Thalmann (2004) dealing with Swiss citizens' votes on environmental policies.

${ }^{21}$ Here again results revealed to be robust to the use of different variables as controls. See footnote 17 .
} 
are substantially confirmed as well. ${ }^{22}$

Hence, as we can see from the probit analysis, even after controlling for the effects of other variables, age seems to be a significant determinant of the attitudes of the respondents towards the environment.

\section{The Model}

As our analysis focuses on intergenerational issues, an overlapping generations model seems to provide a suitable framework. We consider an infinite horizon economy where agents live two periods. We denote by generation $t$ the cohort of agents born at $t$, with $t=1,2,3, \ldots$ Each new-born generation has the same size, that we normalize to 1 , and agents belonging to the same generation are assumed to be identical. As in Bhattacharya and Qiao (2005), the length of the first period of life is given and normalized to 1 , while the length of the second period, $p() \in(0 ; 1)$, depends on the agent's current health condition $h .^{23}$ Therefore, life expectancy of an agent born at $t$ can be written as: $1+p\left(h_{t+1}\right)$.

Alternatively, as the number of agents is large, $p()$ can be seen as the probability of living throughout the whole second period. Moreover $p\left(h_{t}\right)$ can be seen as the old-young ratio at time $t .^{24}$ Usually, in the literature on endogenous longevity $p(h)$ is assumed to exhibit the following properties: ${ }^{25}$

$$
p^{\prime}(h) \geq 0 \forall h, \quad p^{\prime \prime}(h) \leq 0 \forall h, \quad \lim _{h \rightarrow 0} p(h)=0, \quad \lim _{h \rightarrow \infty} p(h)=\bar{p} \leq 1
$$

where the notation $p^{\prime}(h)\left(p^{\prime \prime}(h)\right)$ denotes the first-(second-)order derivative of $p$ w.r.t. $h$.

\footnotetext{
${ }^{22}$ The coefficient of eu15 goes from $99 \%$ to $95 \%$ significance, as well as the the one of living in small towns.

${ }^{23}$ Note that, since $p() \in(0 ; 1)$, the lived portion of the second period is always shorter than the first period's. This implication is realistic, since the first period begins when an agent enters the working age and covers a large part of it, while the second one includes the retirement period (See Section 6 for a numerical transposition of model periods into number of years). Even if life expectancy can be enlarged substantially by improvements in health, it is expectable that in reality the working age increases as well, thus keeping valid the implication of a shorter expected portion of life in the second period.

${ }^{24}$ Differently from others in the existing literature (e.g. Finlay (2006); Chakraborty and Das (2005)), we do not interpret $p()$ as a mortality shock at the end of the first period. The dependence of $p()$ on the second-period health status can be found also on Osang and Sarkar (2005).

${ }^{25}$ See Chakraborty and Das (2005), Osang and Sarkar (2005), Bhattacharya and Qiao (2005), Kalemli-Ozcan, Ryder, and Weil (2000).
} 
Combining the evidence for sizable effects of both environmental quality and health-care expenditure on lifespan, we assume that the representative agent's health status is endogenously determined by the current environmental quality (denoted by an environmental index $E$ ) and by current health-care expenditure $g_{t}: h_{t}=h\left(E_{t} ; g_{t}\right)$. The function $h()$ is assumed to be increasing in its arguments at decreasing rates, i.e. for all $E, g:{ }^{26}$

$$
h() \geq 0, h_{E}^{\prime} \geq 0, h_{g}^{\prime} \geq 0, h_{E E}^{\prime \prime} \leq 0, h_{g g}^{\prime \prime} \leq 0
$$

It is therefore possible to express the length of the second period as a function $\pi\left(E_{t} ; g_{t}\right)$. Combining the properties of $p(h)$ and $h(g ; E)$, the characteristics of the function $\pi\left(E_{t} ; g_{t}\right)$ are summarized by Properties 1 :

Properties 1 (Properties of the longevity function) For the longevity function:

$$
\pi\left(E_{t} ; g_{t}\right) \equiv p\left(h\left(E_{t}, g_{t}\right)\right) \equiv \pi_{t}
$$

the following properties are given:

$$
\begin{aligned}
& \text { 1. } \pi_{x}^{\prime} \geq 0, x=\{E, g\}, \forall E_{t}, g_{t} \\
& \text { 2. } \pi_{x x}^{\prime \prime} \leq 0, x=\{E, g\}, \forall E_{t}, g_{t} \\
& \text { 3. } \pi_{t} \in(0,1) \forall E_{t}, g_{t}
\end{aligned}
$$

\section{Individuals}

As in Ono (2005), since we are not interested in intragenerational issues, we assume that individuals derive utility only from the second-period consumption level. In this way individuals' decision-making can be left apart and we can focus only on the political economic equilibrium. The lifetime utility of the representative agent born at time $t$ is

$$
U_{t}=\pi_{t+1} u\left(c_{t+1}\right)
$$

that is the utility she gets from consumption $c_{t+1}$ weighted by the length of her life. The following assumptions on $u()$ are made

$$
\forall c>0: \quad u(c)>0, \quad u^{\prime}(c) \geq 0, \quad u^{\prime \prime}(c) \leq 0
$$

where the first assumption is sufficient to ensure a worth-living life. ${ }^{27}$

\footnotetext{
${ }^{26}$ Often, only one determinant of health is considered. In Finlay (2006), where the health function has two inputs, the same conditions given in the text are assumed.

${ }^{27}$ See Chakraborty and Das (2005). As it is always possible to add a positive constant to a utility function without altering the preference system this assumption does not seem restrictive.
} 
In the first period of life individuals supply to firms an inelastic amount of labour fixed to 1 and get paid at the competitive wage $w_{t}$. As agents do not consume in the first period, they fully save and in the second period they receive an interest rate $r_{t+1}$ on the top of their total savings $s_{t}$ : the second-period total income before taxation amounts to: $\left(1+r_{t+1}\right) s_{t}$.

In a deterministic set-up, individuals know exactly their lifespan and, in the absence of any altruism, they consume everything during the portion of the second period they live

$$
\pi_{t+1}\left(c_{t+1}+\tau_{t+1}^{o}\right)=\left(1+r_{t+1}\right)\left(w_{t}-\tau_{t}^{y}\right)
$$

where $\tau^{y}$ and $\tau^{o}$ are the lump-sum taxes levied by the government to fund health-care spending and environmental maintenance (see Section 4.1), and $\left(w_{t}-\tau_{t}^{y}\right)$ represents net savings.

When individuals do not know their lifespan with certainty, part of their savings ends up to be "unrealized". In particular, out of the total risen amount $\left(1+r_{t+1}\right) s_{t}$, a part $1-\pi()$ can be unrealized, as it refers to a span where the agent is dead. ${ }^{28}$ The unrealized amount is accordingly

$$
\left(1-\pi_{t+1}\right)\left(1+r_{t+1}\right) s_{t}
$$

. When complete annuity markets are available, a rational non altruistic individual can neutralize the death risk by purchasing annuities (see Pecchenino and Pollard (1997)). ${ }^{29}$ With annuity markets, as long as an agent is alive, she receives an extra rate of return $\mu$ on her savings funded through the unrealized savings of dead purchasers, so that the effective interest on savings is: $1+r_{t+1}+\mu_{t+1}$. Basically, the portion of savings that would be unrealized is used to increase wealth as long as agents are alive. However, the degree of completeness of annuity markets is generally not perfect and can vary among countries and time. ${ }^{30}$ Following Ono (2005) and Pecchenino and Pollard (1997) we assume that only a fraction $\gamma \in(0,1)$ of unrealized savings can be annuitised, while the remaining part, $1-\gamma$, is passed on to the next generation as unintended bequests, $b$. In this general set-up the

\footnotetext{
${ }^{28}$ Looking at $\pi$ as the probability of surviving throughout the whole second period, there is a probability $(1-\pi)$ of un-enjoying the savings.

${ }^{29} \mathrm{~A}$ life annuity is an insurance product by which the insured person receives periodically a sum as long as she lives, in exchange for a premium charge. It allows agents to insure against the risk of outliving their savings, given the uncertainty of her remaining lifetime by pooling the mortality risk across annuity purchasers. See Mitchell et al. (1999).

${ }^{30}$ This may occur for a number of reasons which are surveyed by Brown and Wharshawsky (2001). See also Chakraborty and Das (2005).
} 
agent is subject to the following budget constraint

$$
c_{t+1}+\tau_{t+1}^{o}=\left(1+r_{t+1}+\mu_{t+1}\right)\left(w_{t}+b_{t}-\tau_{t}^{y}\right)
$$

Assuming perfect competition, equilibrium in the annuity markets requires

$$
\mu_{t+1} \pi_{t+1} s_{t}=\gamma\left(1-\pi_{t+1}\right)\left(1+r_{t+1}\right) s_{t}
$$

which means that the total payment in extra return (the l.h.s. of Eq. (4) is equal to the total amount of available funds (the r.h.s. of Eq. (4). Eq. (4) yields the equilibrium excess interest rate

$$
\mu_{t}=\gamma \frac{1-\pi_{t}}{\pi_{t}}\left(1+r_{t}\right)
$$

The portion $(1-\gamma)$ of unrealized savings goes to the next generation as (unintended) bequests:

$$
b_{t+1}=(1-\gamma)\left(1-\pi_{t+1}\right)\left(1+r_{t+1}\right) s_{t}
$$

By combining Eq. (5) with Eq. (4) the agent's budget constraint can be rewritten as:

$$
\begin{aligned}
& \tau_{t+1}^{o}+c_{t+1}=\left(1+r_{t+1}+\mu_{t+1}\right) \quad \times \quad\left(w_{t}+b_{t}-\tau^{y_{t}}\right)= \\
& \quad\left(1+r_{t+1}\right)\left[\frac{(1-\gamma) \pi_{t+1}+\gamma}{\pi_{t+1}}\right] \times[\underbrace{w_{t}+(1-\gamma)\left(1-\pi_{t}\right)\left(1+r_{t}\right) s_{t-1}}_{s_{t}}-\tau_{t}^{y}]
\end{aligned}
$$

In the two extreme cases of complete $(\gamma=1)$ and absent $(\gamma=0)$ annuity markets, the budget constraint simplifies to:

$$
\begin{array}{ll}
\gamma=1: & \tau_{t+1}^{o}+c_{t+1}=\frac{1+r_{t+1}}{\pi_{t+1}}\left(w_{t}-\tau_{t}^{y}\right) \\
\gamma=0: & \tau_{t+1}^{o}+c_{t+1}=\left(1+r_{t+1}\right)\left[w_{t}+\left(1-\pi_{t}\right)\left(1+r_{t}\right) s_{t-1}-\tau_{t}^{y}\right]
\end{array}
$$

When annuity markets are complete, the return on savings is increased in a way inversely proportional to the agent's survival probability. On the other hand, when annuity markets are absent, all the unrealized savings (which are higher the lower is $\pi$ ) are passed on to the next generation. Eq. (7) is the same as Eq. (3): with complete annuity markets the death risk can be neutralized and each individual faces the same budget constraint as in a deterministic set-up. This happens because the effect of annuity markets is basically to shift income from the portion of life that is not lived to the 
lived one. On average, all the income risen from the first-period savings can be used in the portion $\pi$ of the second period, exactly as it happens under certainty. At the other extreme, when annuity markets are complete, the amount of savings that would finance consumption in the portion $1-\pi$ of the second period is transferred to the next generation. ${ }^{31}$ By allowing for incomplete annuity markets by means of the parameter $\gamma$ we are able to take into account both channels.

\section{Firms}

We assume that the total output in the economy, $Y$, is produced by perfectly-competitive profit-maximizer firms adopting a c.r.s. technology with labour $L$ and capital $K: Y_{t}=F\left(K_{t}, L_{t}\right)$. It is possible to rewrite the production function in intensive form, since it is homogeneous of degree one and labour supply is normalized to 1 . Moreover, by assuming that capital fully depreciates after one generation, the production function in intensive form becomes

$$
y_{t}=f\left(k_{t}\right)
$$

where $y_{t}$ and $k_{t}$ are output and capital per worker respectively, and $f(k) \equiv$ $F(K, 1)$. Assuming perfect competition in the factor markets, the profitmaximization problem yields the following factor prices

$$
\begin{aligned}
w_{t} & =f\left(k_{t}\right)-k_{t} f^{\prime}\left(k_{t}\right) \\
r_{t} & =f^{\prime}\left(k_{t}\right)-1
\end{aligned}
$$

\section{Environment and Capital Dynamics}

The state variables of the economy are the environmental quality $E$ and capital $k$. The law of motion of capital is given by the equilibrium relation between savings and investment. ${ }^{32}$ As we have assumed full depreciation of capital, net savings determine the capital stock in the next period

$$
k_{t+1}=s_{t}
$$

As far as the environment is concerned, following Ono (2003) and Jouvet (1995) we assume that the environmental quality can be worsened by economic production and improved by environmental maintenance, according

\footnotetext{
${ }^{31}$ Intuitively, as agents do not know exactly when they die, they tend to keep something away, which is then transferred to their children once they actually die.

${ }^{32}$ Notice that every variable is expressed per young agent and that the young cohort size is constant.
} 
to the following law of motion ${ }^{33}$

$$
E_{t+1}=E_{t}-\eta y_{t}+\nu\left(m_{t}\right), \quad \eta>0
$$

where $m_{t}$ is the investment in environmental maintenance. The parameter $\eta$ is related to the impact of economic production on the environment (e.g. units of emission per unit of production). The function $\nu()$ is increasing in $m_{t}$ and captures the efficiency of environmental investment. While Ono (2005) assumes a linear technology, we model a more general framework, imposing the less restrictive conditions

$$
\forall m: \quad \nu^{\prime}(m) \geq 0 ; \quad \nu^{\prime \prime}(m) \leq 0 .
$$

When $\lim _{m \rightarrow 0} \nu^{\prime}(m) \rightarrow+\infty$, a minimum level of positive environmental maintenance is always needed.

\section{Political-Economic Equilibrium}

In the political economy health-care expenditure and environmental maintenance are provided by the government and funded through lump-sum taxation. We denote such a regime by PE, in contrast with PL. From Section 5 onwards we refer to a social planner economy where also the welfare of future generations is taken into account. In PE the expenditures on healthcare and environmental maintenance are usually chosen by the government under the constraints of limited time horizon and political support.

\subsection{Government}

Assuming that the government is entitled to both health-care and environmental expenditures is fairly reasonable as one can think that each individual is small and see her contribution to maintenance as negligible. ${ }^{34}$ Moreover, the environmental quality can be thought of as a public good, being largely non rival and non excludable. ${ }^{35}$ As regards health-care expenditure, in most

\footnotetext{
${ }^{33}$ Notice that Jouvet (1995) uses a natural decay rate. This avoids unit roots in environmental dynamics but, since it is not well-established that the environment deteriorates spontaneously, following Ono (2003) we do not introduce any natural decay rate.

${ }^{34}$ This approach is the same of John and Pecchenino (1994), while Jouvet, Michel, and Vidal (2000) assume that maintenance is chosen privately.

${ }^{35}$ The sub-optimal provision of environmental maintenance in a decentralized setting is shown by Jouvet, Michel, and Vidal (2000) in the so-called "subscription equilibrium", where each agent takes as given the amount of public good provided by the others.
} 
countries it is principally funded through public funds, with the remarkable exception of the USA, where the private share is larger.

In order to finance health-care and environmental investment, the government levies taxes both on the young and the old to fulfil its budget constraint. For the sake of analytical tractability, we make the assumption that taxes are lump-sum: ${ }^{36}$

$$
\tau_{t}^{y}+\pi_{t} \tau_{t}^{o}=m_{t}+\pi_{t} g_{t}
$$

where $\tau^{y}, \tau^{o}$ denote the tax levied on the young and the old, respectively.

The government aims to maximize the overall welfare of the electorate: its objective is represented by a social welfare function $\Omega_{t}$ equal to a weighted sum of the indirect life-time utility of current voters:

$$
\Omega_{t}=\vartheta_{t} U_{t-1}+U_{t}=\vartheta_{t} \pi_{t} u\left(c_{t}\right)+\pi_{t+1} u\left(c_{t+1}\right)
$$

where $\vartheta_{t}$ stands for the weight that the government assigns to the old generation. Eq. (15) is consistent with a probabilistic voting set-up where electors vote over $\tau_{t}^{i}, m_{t}$, and $g_{t}$ (see de la Croix and Doepke (2009)). ${ }^{37}$

As in Ono (2005), we assume rational expectations and myopic decisionmaking. Rational expectations ensure that the environmental policy taken at time $t$ is consistent with the realized fiscal policy at time $t+1$. Due to myopic decision-making, however, the government ignores the impact of current policies on future political decisions. Put it differently, the government

\footnotetext{
${ }^{36}$ Alternatively, Ono (2005) assumes that the government levies a proportional tax on production, which is then shared between workers and capitalists according to the inputs' share. However, this set-up makes the dynamics more complicated as it involves expectations over future tax-rates, thus making the analytical treatment more difficult and without providing any further substantial insights. Similarly, in order to keep the set-up as simple as possible, we abstract from the possibility that the government could run a deficit by issuing debt securities.

${ }^{37}$ Differently from majority voting where, as long as preferences are single-peaked, each agent votes with probability 1 for a policy and eventually it is the position of the median voter that matters, under probabilistic voting the electors have a probabilistic distribution for voting over different policy-variables. This intuitively accounts for the role of "ideology" in determining the voting choice. Under such a voting scheme the winning party (the government) implements a weighted social welfare function like in Eq. (15). Hence, with respect to majority voting, probabilistic voting allows for a smoother aggregation of preferences and can be applied either when preferences are single-peaked or not. Moreover, majority voting in our framework would imply the implausible outcome of a "dictatorship" of the young, as they are homogeneous and in a greater amount than the old. Nevertheless, our setting can be adapted to a majority voting scheme by assuming that the relative preference for health-care expenditure over environmental maintenance is continuously distributed across the population and increasing in age.
} 
in period $t$ correctly forecasts future policies in period $t+1$, but it ignores the effect that its own decisions have on the equilibrium path. Hence, for example, $g_{t+1}$ is taken as exogenous by the government at time $t$, whereas it will be a control variable for the government at time $t+1$.

Differently from Ono (2005), however, we do not postulate that the old have an exogenous political power; on the contrary we assume that each voter has the same weight, so that $\vartheta_{t}$ is equal to the share of old people in the economy, i.e. $\pi_{t}$. By using Eq. (1) and (2), the objective function of the government can be rewritten as

$$
\Omega_{t}=\pi^{2}\left(E_{t}, g_{t}\right) u\left(c_{t}\right)+\pi\left(E_{t+1}, g_{t+1}\right) u\left(c_{t+1}\right)
$$

While $g_{t}$ has a positive impact on the lifespan of the old, $m_{t}$ is valuable for the life expectancy of the young, since it positively affects $E_{t+1}$ through Eq. (13). The outcome of the voting process is a weighted sum of the interests of these two groups. The weights are not constant but endogenously affected by the process of aging, which shifts political importance towards the elderly electors.

\subsection{Inter-temporal Equilibrium}

The maximization of Eq. in (16) occurs in the context of a competitive economy in intertemporal equilibrium. By substituting into the r.h.s.of Eq. (12) the expression for savings appearing as the last factor in Eq. (6), by replacing the factor prices by means of Eq. (10) and (11), by using Eq. (12) lagged one period to replace for $s_{t-1}$ and finally Eq. (14) to take into account the government budget constraint, the following law of motion for capital holds

$$
k_{t+1}=f\left(k_{t}\right)-k_{t} f^{\prime}\left(k_{t}\right)\left[\gamma+(1-\gamma) \pi\left(E_{t}, g_{t}\right)\right]-\left[m_{t}+\pi\left(E_{t}, g_{t}\right)\left(g_{t}-\tau_{t}^{o}\right)\right]
$$

The environmental law of motion is the same as in Eq. (13).

From Eq. (6), by replacing the market-clearing conditions for factor prices in Eq. (10) and (11) and by using the government budget constraint (14) to get rid of $\tau_{t}^{y}$, we obtain

$$
c_{t+1}=f^{\prime}\left(k_{t+1}\right) k_{t+1}\left(1-\gamma+\frac{\gamma}{\pi_{t+1}}\right)-\tau_{t+1}^{o}
$$

As in Ono (2005), we define an economic intertemporal equilibrium for a given sequence of policy variables $\left\{\tau_{t}^{y}, \tau_{t}^{o}, g_{t}, m_{t}\right\}_{t=1}^{\infty}$ as a sequence of lifespan, allocations and prices $\left\{\pi_{t}, c_{t}, k_{t}, E_{t}, s_{t}, b_{t}, w_{t}, r_{t}, \mu_{t}\right\}_{t=1}^{\infty}$ with initial 
conditions $k_{0}>0, E_{0}>0$, such that individuals' utility is maximized, firms' profits are maximized, the government's budget constraint is met, markets clear and Eq. (17) and (13) hold.

\subsection{Voting over health-care and environmental expenditure}

We write the following Lagrangean for the government's maximization problem

$$
\begin{gathered}
\max _{c_{t}, c_{t+1}, k_{t+1}, E_{t+1}, m_{t}, g_{t}, \tau_{t}^{o}} \Psi \equiv \pi\left(E_{t}, g_{t}\right)^{2} u\left(c_{t}\right)+\pi\left(E_{t+1}, g_{t+1}\right) u\left(c_{t+1}\right)+ \\
+q_{t+1}\left\{f\left(k_{t}\right)-k_{t} f^{\prime}\left(k_{t}\right)\left[\gamma+(1-\gamma) \pi\left(E_{t}, g_{t}\right)\right]-\left[m_{t}+\pi\left(E_{t}, g_{t}\right)\left(g_{t}-\tau_{t}^{o}\right)\right]-k_{t+1}\right\}+ \\
+v_{t+1}\left\{E_{t}-\eta A f\left(k_{t}\right)+\nu\left(m_{t}\right)-E_{t+1}\right\}+\zeta_{t}^{o}\left\{f^{\prime}\left(k_{t}\right) k_{t}\left(1-\gamma+\frac{\gamma}{\pi_{t}}\right)-\tau_{t}^{o}-c_{t}\right\}+ \\
\zeta_{t+1}^{y}\left\{f^{\prime}\left(k_{t+1}\right) k_{t+1}\left(1-\gamma+\frac{\gamma}{\pi_{t+1}}\right)-\tau_{t+1}^{o}-c_{t+1}\right\}
\end{gathered}
$$

The derivation of the first-order conditions for the PE problem, which is shown in details in Appendix B.1, yields the following equations:

$$
\begin{aligned}
\pi_{t} \frac{u^{\prime}\left(c_{t}\right)}{u^{\prime}\left(c_{t+1}\right)} & =\pi_{t+1}\left[1-\gamma+\frac{\gamma}{\pi_{t+1}}\right] \alpha_{t} f^{\prime}\left(k_{t+1}\right) \\
\pi_{t} u^{\prime}\left(c_{t}\right) & =\left[2 u\left(c_{t}\right)-\left(c_{t}+g_{t}\right) u^{\prime}\left(c_{t}\right)\right] \pi_{t, g}^{\prime} \\
\pi_{t} u^{\prime}\left(c_{t}\right) & =\nu^{\prime}\left(m_{t}\right) \pi_{t+1, E}^{\prime}\left[u\left(c_{t+1}\right)-\frac{\gamma u^{\prime}\left(c_{t+1}\right) k_{t+1} f^{\prime}\left(k_{t+1}\right)}{\pi_{t+1}}\right]
\end{aligned}
$$

where the symbol $\alpha_{t} \equiv 1-\left\|\frac{f^{\prime \prime}\left(k_{t}\right) k_{t}}{f^{\prime}\left(k_{t}\right)}\right\|$ is introduced to keep a synthetic notation; $\alpha_{t}$ represents the complement to 1 of the elasticity of marginal productivity of capital. In the particular case of a Cobb-Douglas production function: $y_{t}=A k_{t}^{\alpha}$, then $\forall t \alpha_{t}=\alpha$ and $\alpha$ represents the capital share of output. $^{38}$

Eq. (20) represents the Euler's equation for the PE case. It puts in evidence three main channels through which longevity plays a role on the voting outcome. The first channel is a capital accumulation enhancing effect (represented by $\pi_{t+1}$, the first term on the r.h.s.), which is related to the larger life expectancy of the young generation. The second channel is moving in an opposite direction, hindering capital accumulation: it is due to

\footnotetext{
${ }^{38}$ In Assumption 1.2 we refer to such a particular case for the sake of analytical tractability.
} 
the political weight of the old (represented by $\pi_{t}$ on the l.h.s.), who are less interested to capital accumulation and are net user of health-care provision. The third channel is effective in the presence of annuity markets, it reduces the extra returns on savings since there are more people alive. The degree of completeness of annuity markets is important because this latter effect (represented by $\pi_{t+1}$ inside the square brackets on the r.h.s.) contrasts the first channel and fully offsets it under perfect annuity markets. Since $\pi$ is endogenous, these channels are simultaneously taken into account and the life expectancy itself results from the optimization problem. Keeping longevity constant, an increase in the degree of annuity markets would increase capital accumulation.

Eq. (21) concerns the marginal effects of increasing health-care expenditure. This has a cost for the old in terms of foregone consumption, represented by the 1.h.s. of Eq. (21). On the other side, there is a positive effect since health-care provision enlarges the lifespan of the current old generation, thus increasing its total utility and its political weight (the first term in square brackets in Eq. $(21)^{39}$ ). There is also a negative effect (the second term in square brackets) related to the increased absorption of resources by the old generation, which reduces those available for the young.

The effects of marginal changes in environmental maintenance are shown in Eq. (22). The r.h.s. represents the net gain of increasing $m_{t}$ through its effect on the lifespan of the young generation: this entails a benefit in terms of larger utility and, in the presence of annuity markets, a cost due to lower extra-returns on savings. The l.h.s. shows the cost borne by the old in terms of marginal utility of consumption, when more resources are devoted to maintenance. Such a cost is larger the larger is $\pi_{t}$, because it is related to the political support from the old, who do not benefit from environmental maintenance. ${ }^{40}$

It is now convenient to introduce some assumptions on the explicit functional forms, in order to go further into the analysis. They are summarized in Assumption 1. In Section 6 more general functional forms will be considered by means of numerical examples.

Assumption 1 The following explicit forms and values are assumed:

\footnotetext{
${ }^{39}$ Note the number 2 that is referred to this double effect.

${ }^{40}$ Once again, it is worth remarking that this extreme assumption is done only for the sake of simplicity. The main qualitative effects still hold if also the old benefit from $m_{t}$, as long as they do that to a smaller extent than the young.
} 
1. Utility function is a constant intertemporal elasticity of substitution function (CIES):

$$
u\left(c_{t}\right)=\frac{c_{t}^{1-\sigma}}{1-\sigma}, \quad \sigma \in(0,1)
$$

2. The production function is:

$$
f(k)=A k^{\alpha} \quad A>0, \alpha \in(0,1)
$$

3. The survival function $\pi$ is:

$$
\pi\left(E_{t} ; g_{t}\right)=\varpi g_{t}^{\epsilon} E_{t}^{1-\epsilon}, \quad \epsilon \in(0,1) ; \varpi>0
$$

4. The maintenance technology is linear:

$$
\nu(m)=\zeta m, \quad \zeta>\eta>0
$$

5. Annuity markets are absent:

$$
\gamma=0
$$

Eq. (24) and (23) are quite familiar. The former is the standard CobbDouglas production function, while the latter is a constant intertemporal elasticity of substitution (CIES) utility function, where the parameter $\sigma$ is the inverse of the intertemporal elasticity of substitution of consumption, thus being a measure of preference for consumption smoothing. In a non deterministic set-up, $\sigma$ can also be interpreted as the coefficient of relative risk aversion and Eq. (23) as a constant relative risk aversion (CRRA) utility. The restriction $\sigma \in(0,1)$ is enforced in order to guarantee a positive value for human life, so that life is worth living. ${ }^{41}$

The Assumption 1.3 is useful, because it implies that the elasticity of $\pi_{t}$ with respect to $g_{t}$ is constant and equal to the coefficient $\epsilon$. This specification still satisfies Properties 1.1 and 1.2, while Property 1.3 cannot be satisfied for all $t$ as eventually it would imply a vanishing elasticity. However, since all variables (included $g$ and $E$ ) take a finite value in the steady state, it is always possible to ensure that, by considering a $\varpi$ small enough, $\pi$ is between 0 and 1 in a neighbourhood of the steady state.

\footnotetext{
${ }^{41}$ Such a restriction is made in Chakraborty and Das (2005) as well. This has also the further implication that the savings function is increasing in the gross interest rate. However, in our framework, with no first-period consumption, this effect does not appear.
} 
Concerning Assumption 1.4, a linear maintenance technology is the most used functional form in the reference literature and it implies that the marginal impact of maintenance on environmental quality is constant. ${ }^{42}$ The restrictions on $\eta$ and $\zeta$ are made to guarantee that investing in environmental maintenance is worthwhile and feasible. ${ }^{43}$

Finally, by Assumption 1.5, annuity markets are absent. Besides allowing some simplifications, such a case is not unrealistic as in many countries annuity markets are far from being complete. ${ }^{44}$. This restriction implies that a large amount of unrealized savings is in fact transferred to the currentl young generation. ${ }^{45}$ In Section 6 the role of annuity markets is assessed by allowing for a strictly positive $\gamma$.

By applying Assumption 1.3 to Eq. (21), we have the following proposition:

Proposition 1 Under Assumption 1.3, at any t, the ratio of health-care expenditure over consumption $\left(g_{t} / c_{t}\right)$ is larger for a larger $\epsilon$ and/or for a larger $\sigma$.

Proof: By rearranging Eq. (21) and using Assumption 1:

$$
\frac{g_{t}}{c_{t}}=\frac{1+\sigma}{1-\sigma} \frac{\epsilon}{1+\epsilon}
$$

Proposition 1 states that resources are diverted from consumption towards health-care expenditure when longevity becomes more elastic to healthcare spending. In addiction, health-care expenditure grows relatively to consumption when the preference for consumption smoothing increases or, under the alternative interpretation of $\sigma$, when agents are more risk averse (that is, they prefer to consume less in exchange for a lower risk). In the

\footnotetext{
${ }^{42}$ With such a technology, a corner solution with no maintenance cannot be excluded $a$ priori.

${ }^{43}$ See Eq. (32) hereinafter.

${ }^{44}$ See Brown (1999), Milevskya and Young (2007). The very low level of annuitised assets has been labeled as "annuity puzzle". Possible explanations are the presence of bequest motives, adverse selection issues, risk pooling within family, high load factors by companies, presence of Social Security, inflation risk, ignorance and regulatory impediments (see Brown (1999)). From a technical viewpoint, we could alternatively have obtained some simplifications by assuming the opposite case $(\gamma=1)$ which, however, would have been more unrealistic.

${ }^{45} \mathrm{~A}$ rough way of introducing dynastic bequests in the model could be indeed through a negative shift in $\gamma$.
} 
next paragraph we will focus on the steady-state solution to the PE problem under Assumption 1.

\subsection{PE steady state}

In the steady state, the environmental quality $E$ must be constant. From Eq. (13), we thus have that the level of maintenance is determined only by the relation between cleaning and polluting technology:

$$
m=\nu^{-1}(\eta f(k))
$$

This implies that the following four-equation system is sufficient to determine the steady-state values of $k, c, g, E$ :

$$
\begin{aligned}
1 & =\left(1-\gamma+\frac{\gamma}{\pi}\right) \alpha f^{\prime}(k) \\
f(k)-k-m(k) & =\pi(E, g)(g+c) \\
\frac{g}{c} & =\left(\frac{2 u(c)}{u^{\prime}(c) c}-1\right)\left(\frac{\pi}{\pi_{g}^{\prime} g}+1\right)^{-1} \\
\pi & =\nu^{\prime}(m) \pi_{E}^{\prime}\left[\frac{u(c)}{u^{\prime}(c)}-\frac{\gamma k f^{\prime}(k)}{\pi}\right]
\end{aligned}
$$

where Eq. (29) is obtained from the law of motion of capital (17) evaluated at the steady state and taking into account the consumer's budget constraint (18). Now, let us consider the PE steady state under Assumption 1. Maintenance is given by:

$$
m=\frac{\eta}{\zeta} A k^{\alpha}
$$

while the system (28)-(31) becomes:

$$
\begin{aligned}
f^{\prime}(k) & =\frac{1}{\alpha} \\
\Theta^{P E} \equiv f(k)-k-m(k) & =\pi(E, g)(g+c) \\
\frac{g_{t}}{c_{t}} & =\frac{1+\sigma}{1-\sigma} \frac{\epsilon}{1+\epsilon} \\
\frac{\pi_{g}^{\prime}}{\pi_{E}^{\prime}} & =\zeta \frac{1+\epsilon}{1+\sigma}
\end{aligned}
$$

The 1.h.s. of Eq. (34) represents the PE feasibility set (denoted by $\Theta^{P E}$ ), i.e. what is available for consumption and health-care expenditure, once capital and environmental quality are kept constant. Since $k$ and $m$ can 
now be determined autonomously, $\Theta^{P E}$ is independent of $c, g$ and $E$ and the steady-state values of $m$ and $k$ can be obtained by Eq. (32) and (33), as shown in the following Lemma:

Lemma 1 Under Assumption 1, $k$ does not depend on the environmental parameters, while $m$ is increasing in $\eta$ and decreasing in $\zeta$. The maintenance share of output is constant: $m / y=\eta / \zeta$.

The feasibility set $\Theta^{P E}$ is given by:

$$
\Theta^{P E}=\left(1-\alpha^{2}-\frac{\eta}{\zeta}\right) \underbrace{\left(A^{\frac{1}{1-\alpha}} \alpha^{\frac{2 \alpha}{1-\alpha}}\right.}_{f(k)})
$$

$\Theta^{P E}$ is increasing in $\zeta$ and decreasing in $\eta$.

Proof: $\quad$ From (32) and (33) we have

$$
\begin{aligned}
k & =A^{\frac{1}{1-\alpha}} \alpha^{\frac{2}{1-\alpha}} \\
m & =\frac{\eta}{\zeta} A^{\frac{1}{1-\alpha}} \alpha^{\frac{2 \alpha}{1-\alpha}}
\end{aligned}
$$

The rest of the proposition follows by replacing $m$ and $k$ in the definition of $\Theta^{P E}$ and by taking partial derivatives.

The sub-system (34)-(36) determines $g, c, E$ as an allocation of $\Theta^{P E}$ between $g$ and $c$, such that $E$ is steady and consistent with the optimizing conditions. We can now establish the PE steady-state relation between $E$ and $g$, as presented in the following proposition:

Proposition 2 Under Assumption 1 the ratio between $E$ and $g$ in the PE steady state is:

$$
\frac{E}{g}=\frac{\zeta}{1+\sigma} \frac{(1-\epsilon)(1+\epsilon)}{\epsilon}
$$

$E / g$ is decreasing in $\epsilon$ and $\sigma$, while it is increasing in $\zeta$.

Proof: The result comes from Eq. (36) and partial derivatives.

Proposition 2 confirms two intuitions: if lifespan becomes more elastic with respect to health-care expenditure (a larger $\epsilon$ ), then $g$ will grow relatively to $E$. On the contrary, if maintenance becomes more effective ( a larger $\zeta$ ), then $E$ will grow relatively to $g$. A third result is less intuitive: a greater $\sigma$ reduces $E$ relatively to $g$. The rational behind this is that, when $\sigma$ is large, there is a preference for living longer (see Proposition 1), which 
can be due - according to the interpretation of $\sigma$ - either to risk aversion or to a propensity for consumption smoothing. In the PE case such a goal implies a larger political weight of the old and, hence, a larger increase in health-care spending than environmental quality.

Moreover, Assumption 1 allows to find an explicit solution for all the steady-state variables. They are summarized in the following Lemma, while the intermediary steps are left in the proof.

Lemma 2 The steady-state values of $g, c, E$ and $\pi$ are given respectively by

$$
\begin{aligned}
g & =\sqrt{\frac{\epsilon^{2-\epsilon}(1+\sigma)^{2-\epsilon}}{\zeta^{1-\epsilon}\left(1-\epsilon^{2}\right)^{1-\epsilon}(2 \epsilon+1-\sigma)} \Theta^{P E}} \\
c & =\frac{(1+\epsilon)(1-\sigma) \sqrt{\Theta^{P E}}}{\sqrt{\left(\zeta-\epsilon^{2} \zeta\right)^{1-\epsilon} \epsilon(1+\sigma)^{\epsilon}}(1+2 \epsilon-\sigma)} \\
E & =\frac{\sqrt{\left(\zeta-\epsilon^{2} \zeta\right)^{1+\epsilon} \Theta^{P E}}}{\sqrt{[\epsilon(1+\sigma)]^{\epsilon}(1+2 \epsilon-\sigma)}} \\
\pi & =\varpi \sqrt{\frac{\epsilon\left[\left(1-\epsilon^{2}\right) \zeta\right]^{\frac{1-\epsilon}{2}}(1+\sigma)^{\frac{\epsilon}{2}} \Theta^{P E}}{1+2 \epsilon-\sigma}}
\end{aligned}
$$

Proof: See Appendix C.1.

Since an increase in $\sigma$ makes living longer more desirable, $c$ decreases (see Eq. (42)) and $\pi$ increases (see Eq. (44)). As for the two inputs of $\pi$, the health-care expenditure unambiguously increases (see Eq. (41)), while the environmental quality increases only provided that $\epsilon$ is sufficiently low (see Eq. (43)) ${ }^{46}$, because when $\epsilon$ is very large it is worth pursuing the objective of living longer just through increasing $g$.

If maintenance technology improves (a larger $\zeta$ ), the impact on $E$ is obviously positive, whereas the effects on $g$ and $c$ are ambiguous: on the one hand, there is a negative substitution effect (a better environmental quality becomes "cheaper"), nevertheless on the other hand there is a positive effect since, ceteris paribus, a lower level of $m$ is needed to keep $E$ steady, thus freeing resources and enlarging the feasibility set. The overall impact of $\zeta$ on $\pi$ is however positive. This implies that an improvement in environmental-maintenance technology is always beneficial (see Eq. (44)) for life expectancy, without necessarily increasing health-care expenditure.

\footnotetext{
${ }^{46}$ More precisely: $\partial E / \partial \sigma>0 \Leftrightarrow \epsilon<1 / 2(1+\sigma)$. All the partial derivatives are omitted for the sake of brevity but are available from the authors upon request.
} 


\section{Social Planner Equilibrium}

The PL case represents a first-best approach, which consists in solving the optimization problem of a social planner who takes care of current and future generations. The planner treats each agent within a given generation equally and discounts future generations by an exogenous and constant factor $\rho<1$. The planner's optimization problem differs from the PE solution in three main respects: first, also future generations are taken into account. Second, the weight attached to the welfare of each generation is not affected by the age structure of the population; finally the planner is not constrained by market equilibria.

The objective function of the social planner is as follows:

$$
\max _{c_{t}, m_{t}, g_{t}, k_{t}, E_{t}} \sum_{t=0}^{+\infty} \rho^{t}\left(\frac{\pi_{t} u\left(c_{t}\right)}{\rho}\right)
$$

Such a problem is subject to two constraints. The first one is represented by resource feasibility:

$$
y_{t}=\pi\left(E_{t}, g_{t}\right)\left(c_{t}+g_{t}\right)+m_{t}+k_{t+1}
$$

at each period the outcome has to be divided among consumption, healthcare expenditure, environmental maintenance and capital accumulation. The other resource constraint is the environmental law of motion, given in Eq. (13). The Lagrangean reads:

$$
\begin{aligned}
\ell=\sum_{t=0}^{+\infty} \rho^{t}\{ & \pi\left(E_{t+1}, g_{t+1}\right) u\left(c_{t+1}\right)+\rho q_{t+1}\left(f\left(k_{t}\right)-\pi\left(E_{t}, g_{t}\right)\left(c_{t}+g_{t}\right)-m_{t}-k_{t+1}\right)+ \\
& \left.+\rho v_{t+1}\left(E_{t}-\eta f\left(k_{t}\right)+\nu\left(m_{t}\right)-E_{t+1}\right)+z 1_{t} m_{t}+z 2_{t} g_{t}\right\}
\end{aligned}
$$

with $E_{0}, k_{0}$ given and $m_{t} \geq 0, g_{t} \geq 0$. The Lagrangean multipliers for $k$ and $E$ are, respectively, $q$ and $v$, which represent the shadow values of relaxing the constraints on capital and environment; while $z 1_{t}$ and $z 2_{t}$ are the Khun-Tucker multipliers of environmental maintenance and health-care expenditure respectively which, at interior solutions, are always zero. For the sake of simplicity we focus on interior solutions and work with the Lagrangean at time $t$

$$
\begin{array}{r}
\ell_{t}=\frac{\pi\left(E_{t}, g_{t}\right) u\left(c_{t}\right)}{\rho}+\rho q_{t+1}\left(f\left(k_{t}\right)-\pi\left(E_{t}, g_{t}\right)\left(c_{t}+g_{t}\right)-m_{t}\right)-q_{t} k_{t}+ \\
+\rho v_{t+1}\left(E_{t}-\eta f\left(k_{t}\right)+\nu\left(m_{t}\right)\right)-v_{t} E_{t}
\end{array}
$$


The derivation of the first-order conditions for the PL problem, which is shown in details in Appendix B.2, yields the following equations:

$$
\begin{gathered}
\rho\left(1-\frac{\eta}{\nu^{\prime}\left(m_{t+1}\right)}\right) f^{\prime}\left(k_{t+1}\right)=\frac{u^{\prime}\left(c_{t}\right)}{u^{\prime}\left(c_{t+1}\right)} \\
u^{\prime}\left(c_{t}\right)\left[\pi_{t}+\left(c_{t}+g_{t}\right) \pi_{t, g}^{\prime}\right]=u\left(c_{t}\right) \pi_{t, g}^{\prime} \\
\nu^{\prime}\left(m_{t}\right)\left\{\pi_{t+1, E}^{\prime}\left[u\left(c_{t+1}\right)-u^{\prime}\left(c_{t+1}\right)\left(c_{t+1}+g_{t+1}\right)\right]+\frac{u^{\prime}\left(c_{t+1}\right)}{\nu^{\prime}\left(m_{t+1}\right)}\right\}=\frac{1}{\rho} u^{\prime}\left(c_{t}\right)
\end{gathered}
$$

Eq. (49) is the Euler's equation in an environmental economy with maintenance. Without the environment the terms in parenthesis on the l.h.s. would simply amount to 1 ; with the environment, instead, the polluting effect of production and the contrasting effect of maintenance are taken into account. Eq. (50) highlights the relation between health-care expenditure and consumption; while Eq. (51) shows the optimal condition concerning improving environmental quality through $m$.

\section{Comparison of the PE and PL intertemporal equilibria}

Let us now compare the 3 -equation system for the PL problem (Eq. (49)(51)) with the one for the PE case, i.e., Eq. (20)-(22). These two systems refer to optimal intertemporal conditions in the most general forms: for both cases they are derived under a general equilibrium approach, so that they include indirect effects and are readily comparable. Next, we apply Assumption 1 also to the PL set-up, in order to find the steady-state solution and contrast it with the PE one obtained in Section 4.4.

We start from comparing the conditions concerning capital accumulation, i.e., Eq. (49) and (20). It can be readily seen how different are the forces in place in the two cases. Whereas in PL the polluting effect of production is taken into account, this is not the case in $\mathrm{PE}$ where none of the electors is interested in $E_{t+2}$, thus producing an enhancing effect on capital accumulation. ${ }^{47}$ Another important difference is related to the presence of annuity markets in PE: a higher degree of annuity markets tends to reduce the total savings, because of less intergenerational transfers, but increases the effective returns on them. Note that, using a general equilibrium approach, it is important to make such indirect channel emerge. ${ }^{48}$

\footnotetext{
${ }^{47}$ This effect is partly contrasted by the one operating through $\alpha_{t}$ and going in the opposite direction. In PE, indeed, the incentive to accumulate capital is reduced, as returns are decreasing and factors' owners are remunerated according to the marginal productivity of their respective factor. Such an effect is taken into account by the government in the maximization problem.

${ }^{48}$ In a partial equilibrium set-up the effect of aging on intergenerational bequests or on
} 
As for environmental maintenance, we compare Eq. (22) to Eq. (51). The last term in curly brackets on the l.h.s. of Eq. (51) represents the current shadow-value of $E_{t+2} \cdot{ }^{49}$ Only the planner internalizes the long-lasting beneficial effects of investing in maintenance, whereas the short-lived government is interested only in the effects on $E_{t+1}$, since no current elector is affected by the environment of two periods later. This effect tends to reduce the maintenance investment in PE. However, the planner takes into account also a negative effect of increasing lifespan of the current young generation (the negative term in square brackets in Eq. (51)), i.e. consumption and health-care expenditure in the next period will increase as well, thus absorbing more resources which could be potentially accumulated for future generations. On the one hand, because of its short-term horizon, in PE the government has no concern with such an issue, but on the other hand, it faces the competitive-equilibrium constraint on annuity markets, which implies that a larger lifespan tends to reduce the extra-return on savings. ${ }^{50}$

Finally, the comparison of Eq. (21) and Eq. (50) allows to assess the differences in the relation between health-care expenditure and consumption. They are pretty similar but with a substantial difference: the level of $u\left(c_{t}\right)$ appears doubled in Eq. (50). This occurs because in PE rising $g$ has not only the direct effect of increasing the welfare of the old, but it has also an indirect aging effect of enlarging the number of old electors and their political weight. The difference appears even more clearly under Assumption 1, as can be seen in the following proposition:

Proposition 3 In PL, under Assumption 1, the health-care expenditure to consumption ratio at any $t$ is:

$$
\frac{g_{t}}{c_{t}}=\frac{\sigma}{1-\sigma}\left(\frac{\epsilon}{1+\epsilon}\right)
$$

At any $t$ the ratio of health-care expenditure to consumption is larger in $\boldsymbol{P E}$ than in $P L$.

Proof: Eq. 21 can be rewritten as:

$$
\frac{g_{t}}{c_{t}}=\left(\frac{u\left(c_{t}\right)}{u^{\prime}\left(c_{t}\right) c_{t}}-1\right)\left(\frac{\pi_{t}}{\pi_{t, g}^{\prime} g_{t}}+1\right)^{-1}
$$

annuity-markets returns would have been neglected.

${ }^{49}$ This is formally shown in Appendix B.2: see Eq. (77) and Eq. (80).

${ }^{50}$ Hence, the negative effects of increasing too much lifespan are widely different in $\mathrm{PE}$ and PL. Although these effects go in the same direction, it is not possible to establish $a$ priori which one is greater. 
By using points 1 and 3 of Assumption 1 into the expression above, Eq. (52) is obtained. By comparing Eq. (52) to its PE counterpart, Eq. (27), it is easy to see that the r.h.s. of Eq. (27) is always larger.

In $\mathrm{PL}$, as well as in $\mathrm{PE}$, the $g-c$ ratio is larger the higher are the propensity for consumption smoothing $(\sigma)$ and lifespan elasticity to $g(\epsilon)$. However, this ratio is always greater in PE than in PL, because of a selfreinforcing effect between health-care spending and political support: in $\mathrm{PE}$ an increase in health-care expenditure improves the lifespan of the old generation and enlarges the number of electors supporting health-care expenditure the most. This mutual channel pushes $g_{t}$ higher than in PL, where the weight associated to the interest of each generation is exogenous (captured by the discount factor $\rho$ and not dependent on $\pi$ ).

A remarkable implication of Proposition 3 is that, when $\sigma$ is low, the difference between the two solutions is more remarkable because, whilst the planner substitutes easily health-care with consumption, in the PE framework this is not done since the support for spending in $g$ is kept high by an aging population. Therefore the PE outcome is less sensitive to changes in preferences for consumption smoothing or risk-aversion, as there is a kind of political lock-in effect.

\subsection{PL Steady State}

In PL steady state, $k$ and $m$ can be determined autonomously from the following sub-system derived from Eq. (13) and Eq. (49): ${ }^{51}$

$$
\begin{aligned}
\nu(m) & =\eta f(k) \\
1 & =\rho\left(1-\frac{\eta}{\nu^{\prime}(m)}\right) f^{\prime}(k)
\end{aligned}
$$

The solution is provided in the following Lemma:

Lemma 3 In PL the steady-state level of $k$ does depend on the pollution/maintenance parameters; $k$ is decreasing in $\eta$, while the effect of $\eta$ on $m$ is ambiguous; both $k$ and $m$ are increasing in $\rho$.

Under Assumption 1.4:

- $k$ is increasing in $\zeta ; m$ is decreasing in $\zeta$ (increasing in $\eta$ ) iff: $\eta / \zeta<$ $1-\alpha$. The maintenance share of output is the same as in PE: $\frac{m}{y}=\frac{\eta}{\zeta}$

\footnotetext{
${ }^{51}$ Note that, while in $\mathrm{PE}$ we had to make Assumption (1.5) to isolate $k$ and $m$ from the other equations of the steady-state system, this is not necessary in PL.
} 
- The feasibility set in PL is:

$$
\Theta^{P L} \equiv f(k)-k-m=\left(1-\frac{\eta}{\zeta}\right)(1-\alpha \rho) \underbrace{A\left(A \alpha\left(1-\frac{\eta}{\zeta}\right) \rho\right)^{\frac{\alpha}{1-\alpha}}}_{f(k)}
$$

For $\frac{\eta}{\zeta}<1-\frac{\alpha}{\rho}$, the output $y$ and feasibility set $\Theta$ are both larger in $P L$.

Proof: $\quad$ See Appendix C.2.

Lemma 3 highlights that, if production becomes more polluting (a larger $\eta$ ), the steady-state level of capital is reduced and, under conditions identified in Lemma 3, the environmental maintenance is increased in order to preserve the environmental quality. Similarly, when maintenance technology becomes more effective (a larger $\zeta$ ), capital can increase and, under certain conditions, the environmental maintenance can decrease. The effects of $\zeta$ and $\eta$ on $m$ are ambiguous: on one side it is necessary to spend more on maintenance in order to offset the pollution induced by the same level of production, but on the other side the output itself is reduced, so the amount of available resources is lower. Under Assumption 1.4 we can see that, unless the pollution coefficient is fairly high compared to the maintenance coefficient, an improvement in $\zeta$ allows to reduce $m$ and to have a larger $k$.

Moreover, if the pollution coefficient is sufficiently small compared to the maintenance coefficient, we obtain that the feasibility set is larger in PL $\left(\Theta^{P L}>\Theta^{P E}\right)$, thus implying more resources available for health-care expenditure and consumption. Finally, note that the larger is the weight attached to future generations $(\rho)$, the larger is production as well as environmental maintenance (needed to offset the greater pollution).

Let us now assess, also in the PL case, the steady-state values for the remaining variables, i.e. $E, g$ and $c$, by means of Assumption 1. They are provided by the following system, which defines the allocation of $\Theta^{P L}$ between $c$ and $g$, such that $E$ is steady and optimization conditions are satisfied:

$$
\begin{aligned}
\pi(E, g)(c+g) & =\Theta^{P L} \\
\zeta \pi_{E}^{\prime}\left(\frac{c}{1-\sigma}-c-g\right) & =\frac{1-\rho}{\rho} \\
\frac{g}{c} & =\frac{\sigma}{1-\sigma}\left(\frac{\epsilon}{1+\epsilon}\right)
\end{aligned}
$$


Eq. (56) is the resource constraint, Eq. (58) follows straight from Eq. (52), and Eq. (57) is obtained from Eq. (51). ${ }^{52}$. From this system we can derive the following proposition which contrasts the $E-g$ ratio of PL with that of PE.

Proposition 4 Under Assumption 1, in PL the relative intensity of $E$ with respect to $g$ (i.e., $E / g$ ) is increasing in $\sigma$, while in $P E$ it is decreasing. Provided that $\rho$ is sufficiently large, $E$ is used more intensively in $P L$ than in $P E$.

The $E / g$ ratio reads:

$$
\frac{E}{g}=\left(\frac{\rho(1-\epsilon) \varpi \zeta}{1-\rho}\right)^{\frac{2}{1+\epsilon}}\left(\frac{\Theta^{P L}}{\epsilon(1+\epsilon-\sigma)}\right)^{\frac{1}{1+\epsilon}}
$$

Proof: See Appendix C.3.

Therefore, in PL $\sigma$ is found to have a positive effect on the $E-g$ ratio while its impact is negative in PE (see Proposition 2). Why is this the case? As in $\mathrm{PE}$, a larger $\sigma$, meaning a higher degree of risk-aversion or a greater propensity for consumption smoothing, implies a greater importance of living longer in exchange of giving up some consumption. This objective, however, is pursued by the planner through the health input showing more long-lasting effects, i.e. E. In PE, instead, living longer does come mainly through health-care expenditure, because of the political channel highlighted in the previous section.

Moreover, the PL solution turns out to feature a larger $E-g$ ratio for a sufficiently high $\rho$. Since increasing the environmental quality takes more time than $g$ to improve health conditions but has more persistent effects, the less is discounted the future (the larger $\rho$ ) the greater is the relative advantage of spending on the environment. Hence, provided that the planner does not discount heavily the future, in the long-run the environmental quality will be higher in PL than in PE, where the optimization problem faces a shorter horizon and it is constrained by the political claims of electors caring more for $g .{ }^{53}$

\footnotetext{
${ }^{52}$ More precisely, it is possible to rewrite Eq. (51) as: $\nu^{\prime}\left(m_{t}\right) \pi_{t+1, E}^{\prime}\left[\frac{u\left(c_{t+1}\right)}{u^{\prime}\left(c_{t+1}\right)}-c_{t+1}-g_{t+1}\right]=\frac{1}{\rho} \frac{u^{\prime}\left(c_{t}\right)}{u^{\prime}\left(c_{t+1}\right)}-\frac{\nu^{\prime}\left(m_{t}\right)}{\nu^{\prime}\left(m_{t+1}\right)}$. Then considering all variables in steady state yields Eq. (57).

${ }^{53}$ Note that there are also similarities between the PL and PE solution for the $E-g$ ratio. For instance, in both cases, $E / g$ is increasing in $\zeta$ and decreasing in $\epsilon$. The rationale behind this finding is quite intuitive, since $\zeta$ captures the effectiveness of maintenance while $\epsilon$ is the elasticity of lifespan to health-care expenditure.
} 
Moreover, under Assumption 1 the PL steady state admits an explicit solution just like for the PE case. The following lemma summarizes the roots for the system (56)-(58):

Lemma 4 In PL's steady state, under Assumption 1, the variables E, $g, c$ and $\pi$ are:

$$
\begin{aligned}
E & =\zeta \frac{\rho}{1-\rho} \frac{1-\epsilon}{1+\epsilon-\sigma} \Theta^{P L} \\
g & =\left(\frac{1-\rho}{\rho(1-\epsilon) \zeta}\right)^{\frac{1-\epsilon}{1+\epsilon}}\left(\frac{\epsilon}{(1+\epsilon-\sigma)^{\epsilon}}\right)^{\frac{1}{1+\epsilon}}\left(\Theta^{P L}\right)^{\frac{\epsilon}{1+\epsilon}} \\
c & =\frac{(1-\sigma)(1+\epsilon)}{\sigma}\left(\frac{1-\rho}{\rho(1-\epsilon) \zeta}\right)^{\frac{1-\epsilon}{1+\epsilon}}\left(\frac{1}{(1+\epsilon-\sigma)^{\epsilon}}\right)^{\frac{1}{1+\epsilon}}\left(\frac{\Theta^{P L}}{\epsilon}\right)^{\frac{\epsilon}{1+\epsilon}} \\
\pi & =\left(\frac{\rho}{1-\rho}(1-\epsilon) \zeta\right)^{\frac{1-\epsilon}{1+\epsilon}}\left(\frac{\varpi^{2} \epsilon^{\epsilon} \Theta^{P L}}{1+\epsilon-\sigma}\right)^{\frac{1}{1+\epsilon}}
\end{aligned}
$$

Proof: $\quad$ See Appendix C.4.

As shown in Lemma 4, also in PL an increase in $\sigma$ shifts resources from consumption to the lifespan inputs (i.e.: $E$ and $g$ ). A better environmental maintenance technology $(\zeta)$, for a given $\Theta^{P L}$, shifts resources from $c$ and $g$ to $E$; while a greater elasticity of $\pi$ to $g(\epsilon)$ lowers the environmental quality and increases the health-care expenditure. For a given $\Theta^{P L}$, a larger $\rho$ shifts resources from $g$ and $c$ towards a better environmental quality.

From Eq. (63) it can be seen that the effects of parameters $\rho, \zeta$ and $\sigma$ on $\pi$ are all positive, while the effect of $\epsilon$ is ambiguous, as in the PE case. Since $\pi^{P E}$ does not depend on $\rho$, Eq. (63) can also be read as suggesting that, if $\rho$ is sufficiently high, then $\pi^{P L}$ can be larger than $\pi^{P E}$.

\section{Numerical Analysis}

In this section some restrictions made in Assumption 1 are relaxed and the steady-state values in the two regimes are studied numerically. In this way, on the one hand robustness of results obtained under Assumption 1 can be checked under more general functional forms and, on the other hand the effect of other elements of the model, neglected for analytical tractability, can be assessed. In particular, we refer to the degree of annuity markets' completeness $(\gamma)$ and to the degree of substitutability between $g$ and $E$ for determining health status. 


\subsection{Functional forms and baseline parameterization}

As concerns the maintenance technology, the strict linearity is relaxed by allowing for decreasing returns: ${ }^{54}$

$$
\nu(m)=\zeta m^{\nu} \quad \zeta>\eta>0,0<\nu \leq 1
$$

This implies that, in both regimes, the steady-state level of maintenance is given by: $m=\left(\frac{\eta}{\zeta} A k^{\alpha}\right)^{1 / \nu}$. Clearly, Eq. (32) corresponds to the particular case: $\nu=1$.

Then, we allow for a more general form for the survival function $\pi$ :

$$
\begin{aligned}
\pi(E, g) & =\frac{\lambda+h(E, g)}{1+h(E, g)} \quad \lambda \in(0,1) \\
h(E, g) & \equiv B\left(\beta g^{-\theta}+(1-\beta) E^{-\theta}\right)^{-1 / \theta} ; B>0, \theta>-1
\end{aligned}
$$

Differently from the specification in Assumption 1.3, $\pi()$ in Eq. (65) satisfies all the requirements given in Properties 1 , as it is always between 0 and 1 , increasing and concave in the health condition $h$, which in turn is a constant elasticity of substitution (CES) function in $g$ and $E$ (see Eq. (66)). ${ }^{55}$ The parameter $\theta$ is related to the elasticity of substitution, which is in fact equal to: $\frac{1}{1+\theta} \cdot{ }^{56}$

For the utility and the production functions, the forms specified in Assumption 1.1 and 1.2 are kept. The next step before performing a numerical analysis is assigning reasonable values to the parameters. In order to do that, we proceed as follows: since with no annuity markets $(\gamma=0)$, capital and the environmental maintenance can be determined autonomously, and since the evidence for annuity markets is of limited completeness, ${ }^{57}$, we set the baseline values for technological parameters $\eta, \nu, A, \alpha$ by initially considering $\gamma=0$. This allows to assign them plausible values abstracting from the other parameters (see the left hand side part of Table 3). With the coefficient $\alpha$ set as standard in literature and $A$ chosen as a scale parameter, the

\footnotetext{
${ }^{54}$ Whenever $\nu<1$, Eq. (64) implies that an intertemporal equilibrium with zero maintenance cannot be optimal in either cases.

${ }^{55}$ Under Assumption 3.1, $\pi$ is ensured to be between 0 and 1 only provided that $\varpi$ is small enough. Note, however, that Properties 1 implies an eventually decreasing input elasticity for $\pi$ which cannot be met by Assumption 3.1.

${ }^{56}$ The function expressed in eq. (65) is a particular case of that proposed by Blackburn and Cipriani (2002). Under Eq. (65) and (66) the marginal rate of substitution between $E$ and $g$ is as follows: $\frac{\pi_{E}^{\prime}}{\pi_{g}^{\prime}}=\frac{h_{E}^{\prime}}{h_{g}^{\prime}}=\frac{1-\beta}{\beta}\left(\frac{g}{E}\right)^{1+\theta}$.

${ }^{57}$ See Section 4.4 and footnote 44 .
} 
coefficient for returns on maintenance $\nu$ and the polluting conversion factor $\eta$ are such to yield a steady-state share of environmental maintenance over GDP $(m / y)$ at about $1.27 \%$, which is fairly realistic compared to available data for OECD countries. ${ }^{58}$

Table 3: Baseline values for the parameters of the model.

\begin{tabular}{|cccc|cccccc|}
\hline$A$ & $\alpha$ & $\eta$ & $\nu$ & $\theta$ & $\gamma$ & $\sigma$ & $\beta$ & $\mathrm{B}$ & $\lambda$ \\
\hline 100 & .3 & .01 & .8 & 3 & .165 & .5 & .6 & .25 & .1 \\
\hline
\end{tabular}

The other parameters are given the values as in the right hand side part of Table 3. For $\theta$, which can range from -1 (perfect substitutability) to $+\infty$ (perfect complementarity). ${ }^{59}$, it seems reasonable to assume that health-care expenditure and environmental quality are only imperfect substitutes and exhibit some complementarity to improve the health condition effectively; we take a baseline value of 3 and then we check the effects of allowing for higher substitutability. About $\gamma$, the same value used in Pecchenino and Pollard (1997) is kept: this reflects the value of private pension funds as a percentage of US household net wealth. ${ }^{60}$ Following Ehrlich and Lui (1991), $\sigma$ is set at $1 / 2$, which represents the case of a quadratic utility function. ${ }^{61}$ The value for the health-condition technical coefficient $\beta$ is such to reflect a greater weight for $g$ in determining $h$ and to yield a realistic share of health-care expenditure over GDP. Similarly, the scale parameter $B$ is set to fit plausible values for the $g-y$ ratio and life expectancy. Finally, $\lambda$, which is connected to the floor level for $\pi$, is given a relatively low value, thus implying that a good health status is important to live longer.

In the first row of Table 4 we can see that under this baseline parameterization the $g-y$ ratio is at $10.13 \%$, which is reasonably close to the average of $11 \%$ in OECD high-income countries according to the World Development Indicator (see World Bank (2007)). The baseline value for $\pi$ is $87.76 \%$. As-

\footnotetext{
${ }^{58}$ The value for $\nu$ is chosen also in order to not depart too much from the literature, where a linear maintenance technology is usually assumed.

${ }^{59}$ The Cobb-Douglas technology is equivalent to $\theta \rightarrow 1$.

${ }^{60}$ See also Auerbach, Kotlikoff, and Weil (1992). All changes are slightly magnified but not reversed for larger $\gamma$.

${ }^{61}$ Pestieau, Gregory, and Sato (2006) based on a survey by Browning, Hansen, and Heckman (1999) set a parameter analogous to our $\sigma$ to 0.8 . We assess what happens for larger $\sigma$ when we perturb parameters from the baseline calibration.
} 
suming that a period is made up of 30 years and it takes about 20 years before entering the working age (the model's first period), this implies a life expectancy of about 77 years, which is also fairly close to the average of 79 years in OECD high-income countries according to the World Development Indicator (see World Bank (2007)). ${ }^{62}$

\subsection{Perturbing parameters and discussion}

Given the baseline specification, we numerically assess the impacts of a $20 \%$ change of each parameter on the model's variables and on interesting indicators, such as the welfare level and the shares of output made up of health-care expenditure and environmental maintenance. The results for $\mathrm{PE}$ and PL are shown in Table 4 and 5 respectively; clearly the interest is mainly from a qualitative rather than quantitative viewpoint.

Before contrasting the two regimes, we take advantage of the numerical approach to focus on a specific feature of PE, i.e. the effects of annuity markets which were excluded under Assumption 1. We can see from Table 4 that by introducing annuity markets (i.e., increasing $\gamma$ ), on one side $\pi, E$ and the GDP share of health-care expenditure become lower; while on the other side $k$, the GDP share of environmental maintenance and welfare are larger. The rationale behind this finding is that, with an annuity markets system, agents can be better compensated for mortality risk through an extra return, which permits to increase consumption. One the contrary, without annuities such an option is not available and, ceteris paribus, agents prefer to live longer and to consume less. This explains why with a positive $\gamma$ a lower $\pi$ is achieved (and hence also $g$ and $E$ are decreased accordingly), nevertheless the welfare is larger as more resources are available for consumption and capital accumulation.

Let us move to the comparison between PE and PL. The first step is computing the benchmark values for PL steady state under the baseline setting shown in Table 3. In PL no role is played by $\gamma$, but a new parameter $(\rho)$ must be specified. We solve this issue by setting $\rho$ such that the same lifespan as in the PE benchmark case is matched; it turns out that this value is about 0.85 . Table 5 summarizes the results for PL. From the benchmark row it is confirmed that the same steady-state lifespan of PE is provided by using more environmental quality and less health-care expenditure, thus freeing resources for capital accumulation. Indeed, capital is larger in PL

\footnotetext{
${ }^{62}$ Note that setting $\lambda=0.1$ implies that the minimum level of life expectancy is 53 years, even with a very bad health.
} 
Table 4: The effect of perturbing parameters in the PE case

\begin{tabular}{crrrrrrrr}
\hline & $g$ & $E$ & $k$ & $m$ & $\pi$ & $\pi g / y(\%)$ & $m / y(\%)$ & $U$ \\
\hline Benchmark & 29.88 & 21.81 & 23.8 & 3.28 & 0.88 & 10.13 & 1.27 & 26.86 \\
\hline$\gamma(+)$ & $-0.02 \%$ & $-0.20 \%$ & $0.65 \%$ & $0.24 \%$ & $-0.02 \%$ & $-0.23 \%$ & $0.05 \%$ & $0.08 \%$ \\
$\theta(-)$ & $2.85 \%$ & $-2.67 \%$ & $-0.01 \%$ & $0.00 \%$ & $0.03 \%$ & $2.88 \%$ & $0.00 \%$ & $-0.17 \%$ \\
$\eta(+)$ & $-0.87 \%$ & $-2.00 \%$ & $0.05 \%$ & $25.62 \%$ & $-0.19 \%$ & $-1.07 \%$ & $25.60 \%$ & $-0.23 \%$ \\
$\nu=1$ & $6.65 \%$ & $19.80 \%$ & $-0.39 \%$ & $-21.26 \%$ & $1.52 \%$ & $8.40 \%$ & $-21.17 \%$ & $0.35 \%$ \\
$\sigma(+)$ & $13.63 \%$ & $11.84 \%$ & $-0.35 \%$ & $-0.13 \%$ & $1.36 \%$ & $15.30 \%$ & $-0.03 \%$ & \\
$\beta(+)$ & $5.50 \%$ & $-7.74 \%$ & $-0.06 \%$ & $-0.02 \%$ & $0.25 \%$ & $5.78 \%$ & $0.00 \%$ & $-0.25 \%$ \\
$\lambda(+)$ & $-1.36 \%$ & $-1.37 \%$ & $-0.04 \%$ & $-0.01 \%$ & $0.15 \%$ & $-1.12 \%$ & $0.00 \%$ & $0.15 \%$ \\
$B(+)$ & $-8.09 \%$ & $-8.16 \%$ & $-0.29 \%$ & $-0.11 \%$ & $1.13 \%$ & $-6.96 \%$ & $-0.02 \%$ & $0.98 \%$ \\
$A(+)$ & $13.83 \%$ & $11.86 \%$ & $29.29 \%$ & $38.30 \%$ & $1.37 \%$ & $-10.98 \%$ & $6.70 \%$ & $15.38 \%$ \\
\hline
\end{tabular}

Table 5: The effect of perturbing parameters in the PL case

\begin{tabular}{crrrrrrrr}
\hline & $g$ & $E$ & $k$ & $m$ & $\pi$ & $\pi g / y(\%)$ & $m / y(\%)$ & $U$ \\
\hline Benchmark & 24.1 & 28 & 99.0 & 5.6 & 0.88 & 5.33 & 1.41 & 30.85 \\
\hline$\theta(-)$ & $-0.81 \%$ & $1.85 \%$ & $0.00 \%$ & $0.00 \%$ & $0.02 \%$ & $-0.79 \%$ & $0.00 \%$ & $0.04 \%$ \\
$\eta(+)$ & $-0.61 \%$ & $-1.75 \%$ & $-0.65 \%$ & $25.29 \%$ & $-0.11 \%$ & $-0.53 \%$ & $25.53 \%$ & $-0.32 \%$ \\
$\nu=1$ & $3.84 \%$ & $19.93 \%$ & $1.11 \%$ & $-28.91 \%$ & $0.87 \%$ & $4.40 \%$ & $-29.15 \%$ & $0.59 \%$ \\
$\sigma(+)$ & $22.57 \%$ & $23.26 \%$ & $0.00 \%$ & $0.00 \%$ & $2.29 \%$ & $25.38 \%$ & $0.00 \%$ & \\
$\beta(+)$ & $4.04 \%$ & $-9.10 \%$ & $0.00 \%$ & $0.00 \%$ & $-0.10 \%$ & $3.93 \%$ & $0.00 \%$ & $-0.20 \%$ \\
$\lambda(+)$ & $-1.34 \%$ & $-1.30 \%$ & $0.00 \%$ & $0.00 \%$ & $0.15 \%$ & $-1.19 \%$ & $0.00 \%$ & $0.12 \%$ \\
$B(+)$ & $-7.97 \%$ & $-7.70 \%$ & $0.00 \%$ & $0.00 \%$ & $1.16 \%$ & $-6.89 \%$ & $0.00 \%$ & $0.85 \%$ \\
$A(+)$ & $14.60 \%$ & $13.18 \%$ & $29.53 \%$ & $38.39 \%$ & $1.52 \%$ & $-10.29 \%$ & $6.71 \%$ & $15.15 \%$ \\
$\rho=.9$ & $3.30 \%$ & $16.89 \%$ & $9.22 \%$ & $3.36 \%$ & $0.76 \%$ & $1.37 \%$ & $0.66 \%$ & $0.47 \%$ \\
\hline
\end{tabular}


and consequently also $m$ must be larger, in order to offset pollution. ${ }^{63}$ Given that lifespan is the same but consumption is larger, welfare is higher in PL, which is not surprising since it represents a first-best approach.

By perturbing parameters and comparing the effects in Tables 4 and 5, it can be seen that changes have often the same direction but with some remarkable exceptions. An interesting dissimilarity concerns the health inputs substitutability. In PE when $E$ and $g$ become more easily substitutable (a decrease in $\boldsymbol{\theta}$ ), health-care expenditure increases as there is scope for using $g$ more. Since the weight of the elderly in government's decision is related to $g$, when it becomes easier to compensate environmental degradation with health-care expenditure, the government has the political support to enlarge health-care expenditure and to accept a worse environmental quality (or, put it differently, it is very unpopular in this scenario to reduce $g$ ). The elderly - by supporting the expenditure in $g$ - increase both their lifespan and their political weight more effectively. ${ }^{64}$ In PL instead the opposite is observed: a higher value for $E$, a lower $g$ and a lower share for health-care expenditure. As in PE, $g$ and $E$ can be substituted more easily, but, differently from PE, the planner reduces $g$ of benefit to a larger $E$. This happens because the planner has an horizon which comprehends all the future generations and evaluates more long-lasting policies, whereas in PE the political horizon is shorter and there always exists a strong demand for $g$ by the currently living old. These differences are not welfare neutral: whereas in $\mathrm{PE}$ the greater demand for $g$, though beneficial for life expectancy, has a negative overall effect on welfare (because of the greater reduction in consumption), in PL the shift of balance towards $E$ is welfare-enhancing.

Another remarkable dissimilarity can be found with respect to the polluting coefficient $\boldsymbol{\eta}$. In PL an increase in $\eta$ implies a reduction in $k$ since, as we already know from Lemma 3, the polluting effect of production is taken into account. ${ }^{65} \mathrm{In} \mathrm{PE}$, instead, $k$ is not decreased and it actually rises. In both cases, since production increases and it pollutes more, keeping a good quality of the environment is more costly (in fact the $m-y$ ratio increases), $E$ is consequently lower and lifespan is shorter. Health-care expenditure decreases as well, because the possibility of using it as a substitute is limited.

\footnotetext{
${ }^{63}$ Note that when both $k$ and $m$ increase also the $m-y$ ratio increases, because of more accentuated decreasing returns in production.

${ }^{64}$ In other words, the steady-state results from a sequence of temporary equilibria where the support for health-care spending is larger because there is more scope for using $g$ instead of $E$.

${ }^{65}$ Note that the effect of $\eta$ on $k$ in Lemma 3 was obtained for the general case, without imposing Assumption 1, and it appears to be a fortiori confirmed in Table 5.
} 
The overall effect of an increase in $\eta$ on welfare is thus negative.

The numerical analysis is useful also to assess whether some differences between PE and PL obtained under Assumption 1 are confirmed. In this respect it is interesting to compare the effects of an increase in the riskaversion or preference for consumption smoothing (a larger $\boldsymbol{\sigma}$ ). In both PE and PL, $\pi$ has to increase, thus requiring larger $g$ and $E$ and less capital. However, the impact of $\sigma$ is much larger in PL. This confirms a finding implied in Proposition 3: in PL it is mainly $\sigma$ to determine the allocation of resources in the trade-off between consumption and lifespan, whereas in $\mathrm{PE}$ this allocation is influenced by a further element, that is the combined role of aging and political mechanism which boosts $g$ as the old part of the population increases. Hence, $\pi$ is fairly less sensitive to $\sigma$ in PE than it is in PL. ${ }^{66}$

Moreover, when the environmental-maintenance technology improves up to the linear technology case $(\boldsymbol{\nu}=1)$, a good environmental quality can be achieved with less $m$ and a lower $m-y$ ratio: people afford to live longer and the welfare goes up. However, the increase in the health-care expenditure share is much larger in $\mathrm{PE}$, while the overall improvement in welfare is larger in PL. This happens because in PE a more effective environmental technology is combined with a larger demand for health-care, which pushes up both lifespan and health-care spending thus absorbing too many resources. A final difference concerns the coefficient $\beta$ : its increase makes health-care expenditure more important in determining health condition and, accordingly, $g$ and $g / y$ go up, while $E$ is lower. Lifespan goes slightly up in PE due to the increase in health-care spending, while in PL it goes down. The dissimilarity occurs because in PL $E$ is the main determinant of lifespan; if $g$ becomes more important, then the planner finds optimal to accept a slight reduction in $\pi$. Note in fact that, though in both regimes the welfare goes down, the reduction is smaller in PL.

The perturbation of remaining parameters yields generally similar effects in PL and PE, thus serving also as a robustness check for Assumption 1. A greater TFP $A$ implies a greater $k$ and also a larger $m$ to offset the polluting effect: agents afford both longer lifespan and greater consumption, and despite the growth on health-care expenditure, the $g-y$ ratio is lower because output increases by more. With an improvement in the exogenous minimum-lifespan coefficient $\lambda$, agents afford to live longer ceteris paribus

\footnotetext{
${ }^{66}$ Note that, since $\sigma$ directly affects the utility function, for this parameter it does not make sense to assess the welfare impact, as the functions on which it is computed are inherently different.
} 
with less $g$ and $E$ and the welfare-level is larger. The effect of an improvement in the health technology $B$ is analogous: in the steady state people live longer and are better off, affording that level of life expectancy with a lower investment in $g$ and $E$. Finally the last row of Table 5 assesses the impact of $\rho$. As implied by Lemma 3, it is confirmed that a larger $\rho$ carries out a higher level of $k$ and $m$; lifespan is improved by a larger $g$ and, in particular, by a higher $E$, and the net effect on welfare is therefore clearly positive.

\section{Conclusions}

Both health-care expenditure and good environmental quality contribute to improve people's health condition, although empirical evidence suggests that the relative importance of these two inputs might be age-based, as the care for environmental quality appears to be deeper and larger among the young, while the support for health-care expenditure is usually greater among the elderly part of population. This is likely related to the fact that environmental maintenance takes generally more time to be fully effective, although it can last for a longer time. In the light of that, we have tackled the issue of whether and how an economy where public expenditures on health-care and environmental maintenance (as well as taxation) are voted by agents departs from the solution that a social planner would implement.

We have proposed a general equilibrium model where agents' longevity is endogenously dependent on health status, which is in turn determined by both environmental conditions and health-care expenditure. In the political economy regime, a government representing agents' interests in entitled to the provision of both thealth-care expenditure and environmental maintenance, which find different support according to electors' age. The young and the elderly electors show different preferences towards the composition of public spending: health-care expenditure finds larger support among the latter, while environmental maintenance among the former. As lifespan increases, the size of the elderly enlarges too, thus affecting the policy implemented by the government. In the social planner regime, the variables are chosen in order to maximize a utilitarian social welfare function, consisting of the discounted sum of present and future individuals' lifetime utilities.

The general equilibrium framework has allowed to take into account also indirect channels. A certain life expectancy level is achieved by the planner through a more intensive use of environmental quality, while the political economy sustains a more intensive health-care expenditure. A crucial role 
is played by the political mechanism, which makes endogenously high the support towards health-care expenditure in an aging society. This is also reflected in a resource allocation between health-care expenditure and consumption biased towards the former in the political economy with respect to the planner regime. While in the planner case it is mainly the degree of risk-aversion that determines the trade-off between health-care expenditure and consumption, in the political economy this trade-off is much less sensitive to risk-aversion, because of the "attrition" played by the political channel. Risk-aversion is also important in determining the combination between health-care spending and environmental quality, but with opposite effects in the two regimes, as it increases the weight of environmental quality in the planner economy and the one of health-care spending in the political economy.

By means of explicit functional forms and plausible calibration of parameters, we have found that also the degree of substitutability of health inputs has contrasting implications in the two regimes: it shifts resources towards health-care spending in the political economy and towards environmental quality in the planner economy, thus hindering and enhancing welfare, respectively. Moreover, it has been shown that in the political economy case more capital may be accumulated even if production becomes more polluting; this result, due to short-sightedness, does not occur in the planner case. Instead, increasing the productivity of environmental maintenance may improve life expectancy in both economies, without necessarily increasing the health-care expenditure's share of output. Our analysis has also considered the role played by incomplete annuity markets. We have shown that introducing annuity markets reduces the health-care expenditure's share of GDP and life expectancy, but may eventually increase welfare, by offering a better compensation for mortality-risk.

Extensions of our model are possible in various directions, which can be suggested for further research. The assumption of a public health-care system is congruous with most countries' health system and it has allowed to abstract from individuals' decision-making. Nevertheless, it seems promising to extend the model to encompass the case of a private health-care system. Moreover, though we have focused only on steady-state comparison, the study of transitional dynamics seems interesting as well, in particular within the political economy set-up. In addition, the impact of specific factors, such as consumers' risk aversion, development of annuity markets, technology of environmental cleaning and health production, might be tested through empirical investigation. 


\section{References}

Auerbach, A. J., L. J. Kotlikoff, and D.N. Weil. 1992. "The increasing annuitisation of the elderly - estimates and implications for intergenerational transfers, inequality, and national savings." Working paper series 4182, NBER.

Bell, M., and D. Davis. 2001. "Reassessment of the lethal London fog 1952: novel indicators of acute and chronic consequences of acute exposure to air pollution." Envrionmental Health Perspective 109:389-394.

Bhattacharya, J., and X. Qiao. 2005. "Public and Private Expenditures on Health in a Growth Model." Staff general research papers 12378, Iowa State University, Department of Economics.

Blackburn, Keith, and Giam Pietro Cipriani. 2002. "A model of longevity, fertility and growth." American Economic Review 26:187-204.

Blanchard, O.J. 1985. "Debts, deficits, and finite horizons." Journal of Political Economy 93:223-247.

Brown, Jeffrey R. 1999, Jun. "Are the Elderly Really Over-Annuitised? New Evidence on Life Insurance and Bequests." Working paper series 7193, NBER.

Brown, Jeffrey R., and Mark J. Wharshawsky. 2001, Jan. "LongevityInsured Retirement Distributions from Pensions Plan: Market and Regulatory Issues." Working paper series 8064, NBER.

Browning, M., L.P. Hansen, and J-J. Heckman. 1999. "Micro Data and General Equilibrium Models." In Handbook of Macroeconomics, edited by J.B. Taylor and M. Woodford, Volume 1A, 19-40. Elsevier Science.

Cervellati, Matteo, and Uwe Sunde. 2005. "Human Capital Formation, Life Expectancy, and the Process of Development." American Economic Review 95 (5): 1653-1672 (December).

Chakraborty, S., and M. Das. 2005. "Mortality, Human Capital and Persistent Inequality." Journal of Economic Growth 10:159-192.

Chakraborty, Shankha. 2004. "Endogenous lifetime and economic growth." Journal of Economic Theory 116 (1): 119-137 (May).

Daugbjerg, C., and G.T. Svensen. 2001. Chapter 3 of Green taxation in question: Politics and economic efficiency in environmental regulation. Basingstoke, Hampshire: Palgrave.

de la Croix, D., and O. Licandro. 1999. "Life expectancy and endogenous growth." Economic Letters 65:255-263. 
de la Croix, David, and Matthias Doepke. 2009. "To segregate or to integrate: education politics and democracy." Review of Economic Studies 76 (2): 597-628 (April).

Diamond, P.A. 1965. "National debt in the neoclassical growth model." American Economic Review 55:279-293.

EEA, European Environmental Agency. 2005, April. "The attitudes of European citizens towards environment." Technical Report Special Erobarometer 217 - Wave 62.1 - TNS Opinion \& Social. European Commission. Available at http://ec.europa.eu/public_opinion/archives/ebs/ebs_217_en.pdf.

2007. "Europe's environment - The fourth assessment." Technical Report 1. Available at http://www.eea.europa.eu.

Ehrlich, I., and F. T. Lui. 1991. "Intergenerational Trade, Longevity, and Economic Growth." Journal of Political Economy 99 (5): 1029-59 (October).

Evans, M. F., and V. Smith. 2005. "Do new health conditions support mortality-air pollution effects?" Journal of Environmental Economics and Management 50:496-518.

Finlay, Jocelyn. 2006. "Endogenous Longevity and Economic Growth." Australian National University. Program on the Global Demography of Aging, Working Paper Series No.7.

Fort, R., and D. N. Bunn. 1998. "Whether one votes and how one votes." Public Choice 95:51-62.

Guber, Deborah Lynn. 2001. "Voting Preferences and the Environment in the American Electorate." Society 83 Natural Resources 14 (6): 455469 .

Hazan, Moshe, and Hosny Zoabi. 2006. "Does longevity cause growth? A theoretical critique." Journal of Economic Growth 11 (4): 363-376 (December).

Holman, Mirya R., and Travis G. Coan. 2008. "Voting Green." Social Science Quarterly 89 (December): 1121-1135.

John, A., and R. Pecchenino. 1994. "An overlapping generations model of growth and the environment." Economic Journal 104:1393-1410.

John, A., Pecchenino R., D. Schimmelpfennig, and S. Schreft. 1995. "ShortLived Agents and the Long-Lived Environment." Journal of Public Economics, no. 58:127-141. 
Jouvet, P.-A. 1995, Universite Aix-Marseille III. "Voluntary Contributions with Uncertainty: the Environmental Quality." G.r.e.q.a.m. 97a30.

Jouvet, P.-A., P. Michel, and J.-P. Vidal. 2000. "Intergenerational altruism and the environment." Scandinavian Journal of Economics 91:585-591.

Jouvet, P.-A., P. Pestieau, and G. Ponthière. 2007. "Longevity and environmental quality in an OLG model." Economix working papers 2007-19, University of Nanterre, EconomiX.

Kahn, Matthew E. 2002. "Demographic change and the demand for environmental regulation." Journal of Policy Analysis and Management 21 (1): 45-62.

Kahn, Matthew E., and John G. Matsusaka. 1997. "Demand for Environmental Goods: Evidence from Voting Patterns on California Initiatives." Journal of Law $\&$ Economics 40 (1): 137-73 (April).

Kalemli-Ozcan, S., H. Ryder, and D. Weil. 2000. "Mortality decline, human capital investment and economic growth." Journal of Development Economics 62:1-23.

Katsouyanni, K., G. Touloumi, C. Spix, F. Balducci, S. Medina, G. Rossi, B. Wojtyniak, J. Sunyer, L. Bacharova, J. Schouten, A. Ponka, and H.R. Anderson. 1997. "Short term effects of ambient sulphur dioxide and particulate matter on mortality in 12 European cities: results from time series data from the APHEA project." British Medical Journal 314:1658-1663.

Kunst, A.E., C.W.N. Looman, and J.P. Mackenbach. 1993. "Outdoor air temperature and mortality in the Netherlands: a time series analysis." American Journal of Epistemology 137:331-341.

Milevskya, Moshe A., and Virginia R. Young. 2007. "Annuitization and asset allocation." Journal of Economic Dynamics \& Control 31:31383177 .

Mitchell, Olivia S., James M. Poterba, Mark J. Warshawsky, and Jeffrey R. Brown. 1999. "New Evidence on the Money's Worth of Individual Annuities." American Economic Review 89 (5): 1299-1318 (Dec).

Ono, T. 2003. "Environmental Tax Policy and Long-Run Economic Growth." The Japanese Economic Review 54:203-217.

. 2005. "The Political Economy of Environmental Taxes with an Aging Population." Environmental and Resource Economics 30:165194. 
Ono, Tetsuo, and Yasuo Maeda. 2002. "Sustainable Development in an Aging Economy." Environment and Development Economic 7:9-22.

Osang, Thomas, and Jayanta Sarkar. 2005, September. "Endogenous Mortality, Human Capital and Endogenous Growth." Departmental working papers 0511, Southern Methodist University, Department of Economics.

Pautrel, X. 2008. "Reconsidering the Impact of the Environment on Longrun Growth when Pollution Influences Health and Agents have a Finitelifetime." Environmental \& Resource Economics 40 (1): 37-52 (May).

Pecchenino, R., and P. Pollard. 1997. "The Effects of Annuities, Bequests, and Aging in an Overlapping Generations Model of Endogenous Growth." Economic Journal 107:26-46.

Pestieau, P., P. Gregory, and M. Sato. 2006. "Longevity and Pay-as-you-Go Pensions." Core discussion papers 54.

Pope, C., and al. 2002. "Lung cancer, cardiopulmonary mortality, and longterm exposure to fine particulate air pollution." The Journal of American medical association 287:1132-1141.

Salka, William M. 2001. "Urban-rural conflict over environmental policy in the western United States." American Review of Public Administation $31: 33-48$.

Sartor, F., and D. Rondia. 1983. "Hardness of municipal waters and cardiovascular mortality in four small Belgian towns." In International Symposium. Health effects and interactions of essential and toxic elements. M. Abdulla and B. Nair (eds).

Thalmann, Philippe. 2004. "The Public Acceptance of Green Taxes: 2 Million Voters Express Their Opinion." Public Choice 119 (04): 179217.

Tremblay, Kenneth R. Jr., and Riley E. Dunlap. 1978. "Rural-Urban Residence and Concern with Environmental Quality: A Replication and Extension." Rural sociology 43 (3): 474-91.

Van Liere, Kent D., and Riley E. Dunlap. 1980. "The social bases of environmental concern: a review of hypotheses, explanations, and empirical evidence." Public Opinion Quarterly 44 (2): 181-197.

World Bank. 2007. World Development Indicators. Oxford University Press. 


\section{A Data}

\section{A.1 Dataset}

The data collected for the Special Eurobarometer 217/EB62.1/2004 'Attitudes of European citizens towards the environment (2005) are based on a survey carried out between 27th and 29th November 2004 by an independent consortium, on request of the European Commission, Directorate-General Press and Communication, opinion Polls. The survey covers the population of the 25 nationalities of the EU Member States, resident in each of the Member States and aged 15 years and over. The total sample is made from 24,787 respondents.

In each EU country, a number of sampling points was drawn with probability proportional to population size and to population density. In order to do so, the sampling points were drawn systematically from each of the "administrative regional units", after stratification by individual unit and type of area. They thus represent the whole territory of the countries surveyed, according to the distribution of the resident population of the respective EU- nationalities in terms of metropolitan, urban and rural areas. In each of the selected sampling points, a starting address was drawn, at random. Further addresses were selected as every Nth address by standard random route procedures, from the initial address. In each household, the respondent was drawn, at random (following the closest birthday rule). All interviews have been conducted face-to-face in people's home and in the appropriate national language.

The survey mainly focuses on three area: EU citizens' perception of the environment, questions related to information about the environment and the importance of the environment in the political decision making process. As a whole, from the survey emerges a large agreement about the role that the environment should play in political decisions: almost nine out of ten EU citizens believe that policy makers should take into account environmental concerns when developing policy in other areas such as economy and employment. (p. 33 of the report). Moreover, EU citizens are highly conscious of the determining role the environment plays as far as individual's quality of life is concerned: seven out of ten citizens believe that the environment influences their lives. Social factors have a similar impact, while economic factors are perceived as slightly more important (p. 30). However, EU citizens clearly state they lack information on environmental issues and would like to have more information on solutions (pp. 14 and $16)$. 


\section{A.2 Tests for age-biased environmental care}

The distribution of the the variable envimp across the age groups is shown in Table $6 .{ }^{67}$

Table 6: Importance of the environment in relation to age group.

\begin{tabular}{c|ccccc}
\multirow{2}{*}{ envimp } & \multicolumn{5}{|c}{ Agegroup } \\
& refusal & less than 25 & $25-54$ & $55+$ & Total \\
\hline \hline don't know & 1 & 38 & 164 & 222 & 425 \\
& 1.35 & 1.22 & 1.3 & 2.48 & 1.71 \\
\hline not much or less & 15 & 789 & 2,908 & 2,329 & 6,041 \\
& 20.27 & 25.35 & 23 & 26 & 24.37 \\
\hline a lot or more & 58 & 2,285 & 9,571 & 6,407 & 18,321 \\
& 78.38 & 73.43 & $\mathbf{7 5 . 7}$ & $\mathbf{7 1 . 5 2}$ & 73.91 \\
\hline Total & 74 & 3,112 & 12,643 & 8,958 & 24,787 \\
& 100 & 100 & 100 & 100 & 100
\end{tabular}

Terms on the second row of each block are column percentages

The percentage of the young for whom the environment is an important factor of the quality of life $(75.7 \%)$ is larger than that the old's $(71.52 \%)$. In order to check whether such a difference is statistically significant we carry out the two-sample test of proportion, which tests the equality of proportion between the two groups. The result, shown in Table 7, supports the idea that the difference is significant, so that the young seem to care more about the environment than the old.

Since the previous result could be affected by data aggregation which can hide information, we also perform a correlation test between the most disaggregated, available variables for age (age) and for environmental care (env_imp2). The correlation coefficient turns out to be negative (-0.0269) and statistically significant at $99 \% .{ }^{68}$ Moreover, if the youngest part of the sample is excluded (those who are younger than 25 , not considered in our model), the negative correlation is even stronger (the coefficient being equal to -0.0417) and with the same significance level.

Finally a t-test is performed to compare the mean of the disaggregated variable envimp2 among the two groups of interest (variable agegroup),

\footnotetext{
${ }^{67}$ Table 6 , differently from Table 1 , considers the whole dataset, thus including respondents younger than 25 and those who refused to answer.

${ }^{68}$ Clearly, the test is restricted only to observations when both the variables do not take values such as "refusal" or "don't know".
} 
Table 7: Two-sample test of proportion for $e n v \_i m p=$ "A lot or more" between the young and the old.

Two-sample test of proportion

$\mathrm{x} \equiv(25-54):$ Number of obs $=12643$ $\mathrm{y} \equiv(55+):$ Number of obs $=8958$

\begin{tabular}{|c|c|c|c|c|c|c|}
\hline Variable & Mean & Std. Err. & $\mathrm{z}$ & $\bar{P}>\|z\|$ & $95 \%$ Conf. & Interval] \\
\hline $\mathrm{x}$ & 0.757 & 0.003814 & & & 0.749524 & 0.764476 \\
\hline $\mathrm{y}$ & 0.7152 & 0.004769 & & & 0.705854 & 0.724546 \\
\hline diff & $\begin{array}{c}0.0418 \\
\text { under Ho: }\end{array}$ & $\begin{array}{l}0.006106 \\
0.006060\end{array}$ & 6.8974 & 0.000 & 0.029832 & 0.053768 \\
\hline \multicolumn{2}{|c|}{$\begin{array}{l}\operatorname{diff}=\operatorname{prop}(\mathrm{x})-\operatorname{prop}(\mathrm{y}) \\
\text { Ho: diff }=0\end{array}$} & & & & & $\mathrm{z}=6.8974$ \\
\hline $\begin{array}{l}\text { Ha: diff }< \\
\operatorname{Pr}(Z<z)\end{array}$ & & $\begin{array}{l}\text { Ha: } \\
\operatorname{Pr}(\|Z\|<\end{array}$ & $\begin{array}{l}!=0 \\
=0.0000\end{array}$ & & & $\begin{array}{r}\text { Ha: } \operatorname{diff}>0 \\
\operatorname{Pr}(\mathrm{Z}>\mathrm{z})=0.0000\end{array}$ \\
\hline
\end{tabular}

as this test is more suitable than the two-sample test of proportion when the variable of interest can take several values with an ordinal meaning. ${ }^{69}$ The results shown in Table 8 confirm that the means of the two groups of interest (the young (25-54) and the old (55+)) are statistically different from each other, with the young showing a greater concern for the environmental conditions.

Table 8: t-test for means of env_imp2 between young and old

Two-sample $t$ test with unequal variances

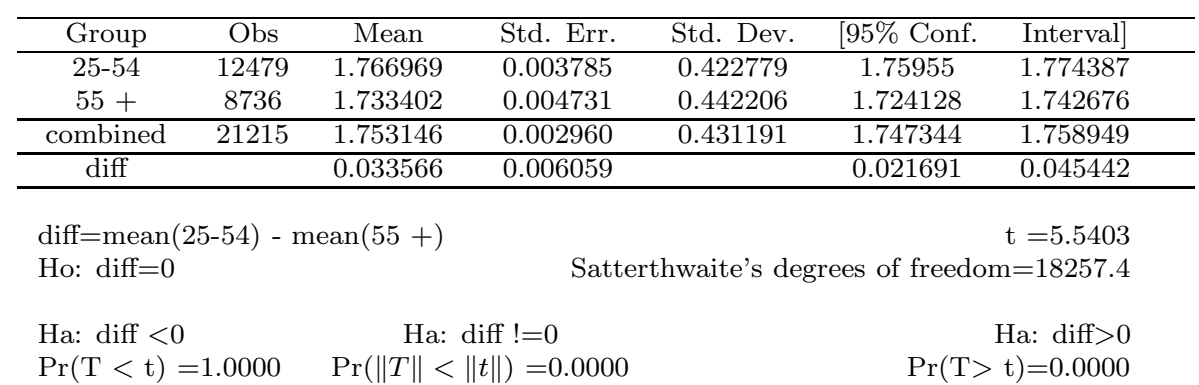

\footnotetext{
${ }^{69}$ Actually, the test fits best for continuous variables. Even if env_imp2 is not continuous, it can be tested better by this test than by the test of proportion, where only two values can be compared.
} 


\section{B Derivation of the first order conditions}

\section{B.1 First order conditions in the PE case}

The first order conditions of $\Psi$ with respect to $c_{t}, c_{t+1}, \tau_{t}^{o}, m_{t}, k_{t+1}, E_{t+1}, g_{t}$ are as follows:

$$
\begin{aligned}
& \zeta_{t}^{o}=\pi_{t}^{2} u^{\prime}\left(c_{t}\right) \\
& \zeta_{t+1}^{y}=\pi_{t+1} u^{\prime}\left(c_{t+1}\right) \\
& \zeta_{t}^{o}=q_{t+1} \pi_{t} \\
& q_{t+1}=v_{t+1} \nu^{\prime}\left(m_{t}\right) \\
& q_{t+1}=\zeta_{t+1}^{y}\left[1-\gamma+\frac{\gamma}{\pi_{t+1}}\right]\left[f^{\prime}\left(k_{t+1}\right)+k_{t+1} f^{\prime \prime}\left(k_{t+1}\right)\right] \\
& v_{t+1}=\pi_{t+1, E}^{\prime}\left[u\left(c_{t+1}\right)-\frac{k_{t+1} \gamma \zeta_{t+1}^{y} f^{\prime}\left(k_{t+1}\right)}{\pi_{t+1}^{2}}\right] \\
& q_{t+1} \pi_{t}=\pi_{t, g}^{\prime}\left[2 \pi_{t} u\left(c_{t}\right)-\frac{\gamma k_{t} f^{\prime}\left(k_{t}\right) \zeta_{t}^{o}}{\pi_{t}^{2}}-q_{t+1}\left[(1-\gamma) f^{\prime}\left(k_{t}\right) k_{t}+g_{t}-\tau_{t}^{o}\right]\right]
\end{aligned}
$$

From the first two equations it follows that $\zeta_{t}^{o}=\pi\left(E_{t}, g_{t}\right) \zeta_{t}^{y}$ : as aging increases the relative shadow value assigned to consumption of the old increases as well. From Eq. (70), the marginal improvement brought about on the environment by a larger maintenance must be equal to its relative "price", expressed by the ratio of the Lagrangean multipliers. From Eq. (71), the marginal cost of accumulating one more unit of capital equates the marginal benefit of enhancing next period consumption.

By getting rid of Lagrangean multipliers through substitution, we get:

$$
\begin{gathered}
\pi_{t} u^{\prime}\left(c_{t}\right)=u^{\prime}\left(c_{t+1}\right)\left[(1-\gamma) \pi_{t+1}+\gamma\right]\left[f^{\prime}\left(k_{t+1}\right)+k_{t+1} f^{\prime \prime}\left(k_{t+1}\right)\right] \\
\frac{\pi_{t} u^{\prime}\left(c_{t}\right)}{\nu^{\prime}\left(m_{t}\right)}=\pi_{t+1, E}^{\prime}\left[u\left(c_{t+1}\right)-\frac{\gamma u^{\prime}\left(c_{t+1}\right) k_{t+1} f^{\prime}\left(k_{t+1}\right)}{\pi_{t+1}}\right] \\
\pi_{t} u^{\prime}\left(c_{t}\right)=\pi_{t, g}^{\prime}\left\{2 u\left(c_{t}\right)-u^{\prime}\left(c_{t}\right)\left[(1-\gamma) f^{\prime}\left(k_{t}\right) k_{t}+g_{t}-\tau_{t}^{o}\right]-\frac{\gamma k_{t} f^{\prime}\left(k_{t}\right)}{\pi_{t}} u^{\prime}\left(c_{t}\right)\right\}
\end{gathered}
$$

Using $\alpha_{t} \equiv 1-\left\|\frac{f^{\prime \prime}\left(k_{t}\right) k_{t}}{f^{\prime}\left(k_{t}\right)}\right\|$, Eq. (74) can be written as Eq. (20); while, rearranging Eq. (75), Eq. (22) can be obtained.

Eq. (76) show on the l.h.s. the cost in terms of foregone consumption of increasing $g_{t}$ for the old; while on the r.h.s. wee see the net benefit due to a larger lifespan. On top of the effect on $u\left(c_{t}\right)$, which can be observed as the 
first term in the curly brackets, in presence of imperfect annuity markets, two further effects are at work: first, the extra-return for the surviving old is lower because there are more people alive. ${ }^{70}$ Second, there are less bequests accruing to the young, which lowers their savings. The former (latter) effect is greater the higher (lower) is the degree of completeness of annuity markets. Eq. (76) can be simplified by replacing $\tau_{t}^{o}$ from the consumer's budget constraint, obtaining Eq. (21).

\section{B.2 First order conditions in the PL case}

Taking derivatives of $\ell_{t}$ in Eq. (48) w.r.t. $c_{t}, E_{t}, k_{t}, m_{t}$ and $g_{t}$, at interior solutions, we have:

$$
\begin{array}{rll}
\frac{\partial \ell_{t}}{\partial c_{t}}: & q_{t+1}=\frac{u^{\prime}\left(c_{t}\right)}{\rho^{2}} \\
\frac{\partial \ell_{t}}{\partial E_{t}} & : \quad v_{t}-\rho v_{t+1}=\left(\frac{u\left(c_{t}\right)}{\rho}-q_{t+1}\left(c_{t}+g_{t}\right) \rho\right) \pi_{t, E}^{\prime} \\
\frac{\partial \ell_{t}}{\partial k_{t}} & : \quad & f^{\prime}\left(k_{t}\right)\left(q_{t+1}-\eta v_{t+1}\right) \rho=q_{t} \\
\frac{\partial \ell_{t}}{\partial m_{t}} & : \quad & \frac{q_{t+1}}{v_{t+1}}=\nu^{\prime}\left(m_{t}\right) \\
\frac{\partial \ell_{t}}{\partial g_{t}} & : \quad \pi_{t} q_{t+1} \rho=\left(\frac{u\left(c_{t}\right)}{\rho}-q_{t+1} \rho\left(c_{t}+g_{t}\right)\right) \pi_{t, g}^{\prime}
\end{array}
$$

Eq. (77) can be compared to its counterpart in the PE case, which can be obtained by combining Eq. (69) and (67): $q_{t+1}=\pi\left(E_{t}, g_{t}\right) u^{\prime}\left(c_{t}\right)$. The shadow value of capital is always less in $\mathrm{PE}$ since $\rho^{-2}>\pi\left(E_{t}, g_{t}\right)$, given that $\rho, \pi \in(0,1)$. In PL relaxing the constraint on capital accumulation in order to consume more today is more costly, because more generations are taken into account.

Eq. (78) states that the current value of the depreciation of $E$ must be equal to the marginal increase in lifespan due to a better environment, which has a positive effect in terms of utility and a negative one in terms of absorption of resources. Eq. (79) shows that the upfront cost of accumulating capital (the r.h.s.) must be equal to the discounted gain which derives from a greater production, net of the negative effect of pollution. Eq. (80) is the same as Eq. (70), so that the PE relation between the shadow values of capital and maintenance is preserved. Finally Eq. (81) relates the price

\footnotetext{
${ }^{70}$ Under the deterministic interpretation this can be seen as the reduction in consumption that agents face in exchange for living longer.
} 
of devoting resources to health-care to its effect in terms of higher lifespan. Again, this is twofold: on one side it is positive in terms of higher utility, on the other side it absorbs more resources.

By eliminating the Lagrangean multipliers through substitutions and shifting the time notation, it is possible to reduce the system (77)-(81) to the system (49)-(51).

\section{Proofs for Lemmas and Propostions}

\section{C.1 Proof of Lemma 2}

By using (35) in (34) we get

$$
g \pi\left(\frac{2 \epsilon+1-\sigma}{(1+\sigma) \epsilon}\right)=\Theta^{P E}
$$

replacing for $\pi$

$$
g E\left(\frac{g}{E}\right)^{\epsilon}\left(\frac{2 \epsilon+1-\sigma}{(1+\sigma) \epsilon}\right)=\Theta^{P E}
$$

let us now divide and multiply by $g$ the l.h.s, we get:

$$
g^{2}\left(\frac{E}{g}\right)^{1-\epsilon}=\frac{(1+\sigma) \epsilon}{2 \epsilon+1-\sigma} \Theta^{P E}
$$

by using eq. (40), we can replace the ratio $E / g$ and finally solve with respect to $g$

$$
g=\left(\frac{\epsilon^{2-\epsilon}(1+\sigma)^{2-\epsilon}}{\zeta^{1-\epsilon}\left(1-\epsilon^{2}\right)^{1-\epsilon}(2 \epsilon+1-\sigma)} \Theta^{P E}\right)^{\frac{1}{2}}
$$

As far as $c$ and $E$ are concerned, they are simply obtained by plugging eq. (41) into eq. (35) and eq. (40), respectively. Once $E$ is known, $\pi$ can be easily computed by replacing the values of $g$ and $E$.

\section{C.2 Proof of Lemma 3}

Applying Assumption 1 to Eq. (53) and (54), and solving with respect to $k$ and $m$, yields:

$$
k=\left(A \alpha\left(1-\frac{\eta}{\zeta}\right) \rho\right)^{\frac{1}{1-\alpha}} \quad ; \quad m=\frac{A \eta}{\zeta}\left(A \alpha\left(1-\frac{\eta}{\zeta}\right) \rho\right)^{\frac{\alpha}{1-\alpha}}
$$


The effects of $\rho$ and $\eta$ on $k$ and $m$ are derived from total differentiation of Eq. (53) and (54) w.r.t. $k, m, \rho, \eta$. They are summarized in the following matrix:

$$
\left[\begin{array}{c}
d k \\
d m
\end{array}\right]=\left[\begin{array}{cc}
\frac{f^{\prime}(k)\left(\eta-\nu^{\prime}(m)\right) \nu^{\prime}(m)^{2}}{-\rho\left(\eta-\nu^{\prime}(m)\right) \nu^{\prime}(m)^{2} f^{\prime \prime}(k)+\eta^{2} \rho f^{\prime}(k)^{2} \nu^{\prime \prime}(m)} & \frac{f^{\prime}(k)\left(\nu^{\prime}(m)^{2}-\eta f(k) \nu^{\prime \prime}(m)\right)}{\left.\nu^{\prime}(m)^{2} f^{\prime \prime}(k)\left(\nu^{\prime}(m)-\eta\right)+\eta^{2} f^{\prime}(k)\right)^{2} \nu^{\prime \prime}(m)} \\
\frac{\eta f^{\prime}(k)^{2}\left(\eta-\nu^{\prime}(m)\right) \nu^{\prime}(m)}{-\rho\left(\eta-\nu^{\prime}(m)\right) \nu^{\prime}(m)^{2} f^{\prime \prime}(k)+\eta^{2} \rho f^{\prime}(k)^{2} \nu^{\prime \prime}(m)} & \frac{\nu^{\prime}(m)\left(\eta f^{\prime}(k)^{2}+f(k)\left(\nu^{\prime}(m)-\eta\right) f^{\prime \prime}(k)\right)}{\nu^{\prime}(m)^{2} f^{\prime \prime}(k)\left(\nu^{\prime}(m)-\eta\right)+\eta^{2} f^{\prime}(k)^{2} \nu^{\prime \prime}(m)}
\end{array}\right]\left[\begin{array}{c}
d \rho \\
d \eta
\end{array}\right]
$$

In order to have a positive steady state, $\nu^{\prime}(m)$ must be larger than $\eta .^{71}$ Given the properties of $f()$ and $\nu()$, the following results hold

$$
\frac{\partial k}{\partial \rho}>0 ; \frac{\partial k}{\partial \eta}<0 ; \frac{\partial m}{\partial \rho}>0
$$

Under Assumption 1.4, the first derivative of $\nu(m)$ is constant and the solution can be found explicitly. If $\frac{\eta}{\zeta}=1-\frac{\alpha}{\rho}$, both output $y$ and its portion used for consumption and health care expenditure $(\Theta / y)$ are the same in $\mathrm{PE}$ and PL, as can be checked by looking at Eq. (55) and (37); If $\frac{\eta}{\zeta}<1-\frac{\alpha}{\rho}$, $y$ and $\Theta$ are larger in PL; if $\frac{\eta}{\zeta}>1-\frac{\alpha}{\rho}$ the opposite occurs.

\section{C.3 Proof of Proposition 4}

By multiplying and dividing both sides of Eq. (57) by $g$ and $\pi$, and using Eq. (58), one obtains

$$
\frac{E}{g}=\zeta \frac{\rho}{1-\rho} \frac{1-\epsilon}{\epsilon} \pi
$$

Replacing Eq. (25) for $\pi$ into the expression above yields:

$$
g^{(1+\epsilon)}=E^{\epsilon} \frac{\epsilon}{1-\epsilon} \frac{1-\rho}{\rho} \frac{1}{\zeta \varpi}
$$

now let us divide both sides by $g$, multiply and divide the r.h.s by $E$. After rearranging, we have:

$$
\left(\frac{E}{g}\right)^{\epsilon}=\frac{1-\epsilon}{\epsilon} \frac{\rho}{1-\rho} \zeta \varpi \frac{g}{E} E
$$

or:

$$
\left(\frac{E}{g}\right)^{(1+\epsilon)}=\frac{1-\epsilon}{\epsilon} \frac{\rho}{1-\rho} \zeta \varpi E
$$

\footnotetext{
${ }^{71}$ Notice that Assumption 1.4 satisfies this requirement.
} 
The steady state value of $E$ can be found by dividing side by side Eq. (82) by Eq. (56), multiplying both sides by $g$ and finally using $c / g$ from Eq. (58):

$$
E=\zeta \frac{\rho}{1-\rho} \frac{1-\epsilon}{1+\epsilon-\sigma} \Theta^{P L}
$$

Using this finding to replace $E$ on the r.h.s of Eq. (83), after some algebraical manipulations we get Eq. (59).

In order to compare the $E-g$ ratio between PE and PL we take the ratio between Eq. (59) Eq. (40). The $E-g$ ratio is larger in PL if and only if:

$$
(1-\epsilon)^{\frac{1-\epsilon}{1+\epsilon}} \epsilon^{\frac{\epsilon}{1+\epsilon}}(1+\epsilon)(1+\sigma)(1+\epsilon-\sigma)^{-\frac{1}{1+\epsilon}}>\left(\frac{1-\rho}{\varpi \rho}\right)^{\frac{2}{1+\epsilon}}\left(\frac{1}{\Theta^{P L}}\right)^{\frac{1}{1+\epsilon}}
$$

The 1.h.s turns out to be always greater than 1 but for very low (and not realistic) values of $\sigma$, while the r.h.s is always lower than 1 unless $\rho$ and $\Theta^{P L}$ (which depends positively on $\rho$ ) are very low. Within a wide range of reasonable values for parameters the inequalities turns out to be satisfied.

\section{C.4 Proof of Lemma 4}

The value of $E$ is given by Eq. (84). Once $E$ is known, $g$ can be obtained from Eq. (82). Finally, with $g$ known, $c$ can be obtained from Eq. (58). Eq. (63) can be derived from Eq. (82) after replacing the l.h.s with the expression in Eq. (59) and some computations. 


\section{Recent titles \\ CORE Discussion Papers}

2008/82. Jean-Sébastien TANCREZ, Benoît ROLAND, Jean-Philippe CORDIER and Fouad RIANE. How stochasticity and emergencies disrupt the surgical schedule.

2008/83. Peter RICHTÁRIK. Approximate level method.

2008/84. Çağatay KAYI and Eve RAMAEKERS. Characterizations of Pareto-efficient, fair, and strategy-proof allocation rules in queueing problems.

2009/1. Carlo ROSA. Forecasting the direction of policy rate changes: The importance of ECB words.

2009/2. Sébastien LAURENT, Jeroen V.K. ROMBOUTS and Francesco VIOLANTE. Consistent ranking of multivariate volatility models.

2009/3. Dunia LÓPEZ-PINTADO and Juan D. MORENO-TERNERO. The principal's dilemma.

2009/4. Jacek B. KRAWCZYK and Oana-Silvia SEREA. A viability theory approach to a two-stage optimal control problem of technology adoption.

2009/5. Jean-François MERTENS and Anna RUBINCHIK. Regularity and stability of equilibria in an overlapping generations model with exogenous growth.

2009/6. Nicolas GILLIS and François GLINEUR. Using underapproximations for sparse nonnegative matrix factorization.

2009/7. Michel M. DENUIT, Louis EECKHOUDT and Mario MENEGATTI. Correlated risks, bivariate utility and optimal choices.

2009/8. Michel M. DENUIT, Louis EECKHOUDT and Mario MENEGATTI. Adding independent risks in an insurance portfolio: which shape for the insurers' preferences?

2009/9. Antoine BOMMIER and Stéphane ZUBER. The Pareto principle of optimal inequality.

2009/10. Raouf BOUCEKKINE, Jacek B. KRAWCZYK and Thomas VALLEE. Environmental negotiations as dynamic games: Why so selfish?

2009/11. Théophile T. AZOMAHOU, Raouf BOUCEKKINE and Phu NGUYEN-VAN. Promoting clean technologies under imperfect competition.

2009/12. Patrice PIERETTI and Skerdilajda ZANAJ. On tax competition, public goods provision and jurisdictions' size.

2009/13. Jeroen V.K. ROMBOUTS and Lars STENTOFT. Bayesian option pricing using mixed normal heteroskedasticity models.

2009/14. Gauthier de MAERE d'AERTRYCKE and Yves SMEERS. The valuation of power futures based on optimal dispatch.

2009/15. Thierry BRECHET, Tsvetomir TSACHEV and Vladimir M. VELIOV. Prices versus quantities in a vintage capital model.

2009/16. François VANDERBECK and Laurence A. WOLSEY. Reformulation and decomposition of integer programs.

2009/17. Marc FLEURBAEY, Erik SCHOKKAERT and Koen DECANCQ. What good is happiness?

2009/18. David DE LA CROIX and Michel LUBRANO. The tradeoff between growth and redistribution: ELIE in an overlapping generations model.

2009/19. Thierry BRECHET and Fabien PRIEUR. Can education be good for both growth and the environment?

2009/20. Giacomo SBRANA and Andrea SILVESTRINI. What do we know about comparing aggregate and disaggregate forecasts?

2009/21. Marc GERMAIN, Henry TULKENS and Alphonse MAGNUS. Dynamic core-theoretic cooperation in a two-dimensional international environmental model.

2009/22. Claude D'ASPREMONT and Rodolphe DOS SANTOS FERREIRA. Household behavior and individual autonomy.

2009/23. Helmuth CREMER, Philippe DE DONDER and Pierre PESTIEAU. Education and social mobility.

2009/24. Maria Eugenia SANIN and Francesco VIOLANTE. Understanding volatility dynamics in the EU-ETS market: lessons from the future.

2009/25. Marco DI SUMMA and Laurence A. WOLSEY. Lot-sizing with stock upper bounds and fixed charges. 


\section{Recent titles}

\section{CORE Discussion Papers - continued}

2009/26. Johanna M.M. GOERTZ and François MANIQUET. On the informational efficiency of simple scoring rules.

2009/27. Jean GABSZEWICZ, Ornella TAROLA and Skerdilajda ZANAJ. On uncertainty when it affects successive markets.

2009/28. Jerzy A. FILAR, Jacek B. KRAWCZYK and Manju AGRAWAL. On production and abatement time scales in sustainable development. Can we loosen the sustainability screw ?

2009/29. María Eugenia SANIN and Skerdilajda ZANAJ. Clean technology adoption and its influence on tradeable emission permit prices.

2009/30. Antoine BOMMIER, Marie-Louise LEROUX and Jean-Marie LOZACHMEUR. On the public economics of annuities with differential mortality.

2009/31. Gilles GRANDJEAN, Ana MAULEON and Vincent VANNETELBOSCH. Connections among farsighted agents.

2009/32. Axel GAUTIER and Xavier WAUTHY. On the nature of price competition under universal service obligations: a note.

2009/33. Santanu S. DEY and Laurence A. WOLSEY. Constrained infinite group relaxations of MIPs.

2009/34. Jean-François MAYSTADT and Philip VERWIMP. Winners and losers among a refugeehosting population.

2009/35. Pierre DEHEZ. Allocation of fixed costs and the weighted Shapley value.

2009/36. Sabien DOBBELAERE, Roland Iwan LUTTENS and Bettina PETERS. Starting an R\&D project under uncertainty.

2009/37. Carlotta BALESTRA and Davide DOTTORI. Aging society, health and the environment.

\section{Books}

H. TULKENS (ed.) (2006), Public goods, environmental externalities and fiscal competition. New York, Springer-Verlag.

V. GINSBURGH and D. THROSBY (eds.) (2006), Handbook of the economics of art and culture. Amsterdam, Elsevier.

J. GABSZEWICZ (ed.) (2006), La différenciation des produits. Paris, La découverte.

L. BAUWENS, W. POHLMEIER and D. VEREDAS (eds.) (2008), High frequency financial econometrics: recent developments. Heidelberg, Physica-Verlag.

P. VAN HENTENRYCKE and L. WOLSEY (eds.) (2007), Integration of AI and OR techniques in constraint programming for combinatorial optimization problems. Berlin, Springer.

P-P. COMBES, Th. MAYER and J-F. THISSE (eds.) (2008), Economic geography: the integration of regions and nations. Princeton, Princeton University Press.

J. HINDRIKS (ed.) (2008), Au-delà de Copernic: de la confusion au consensus ? Brussels, Academic and Scientific Publishers.

\section{CORE Lecture Series}

C. GOURIÉROUX and A. MONFORT (1995), Simulation Based Econometric Methods.

A. RUBINSTEIN (1996), Lectures on Modeling Bounded Rationality.

J. RENEGAR (1999), A Mathematical View of Interior-Point Methods in Convex Optimization.

B.D. BERNHEIM and M.D. WHINSTON (1999), Anticompetitive Exclusion and Foreclosure Through Vertical Agreements.

D. BIENSTOCK (2001), Potential function methods for approximately solving linear programming problems: theory and practice.

R. AMIR (2002), Supermodularity and complementarity in economics.

R. WEISMANTEL (2006), Lectures on mixed nonlinear programming. 